\title{
Smart Rotorcraft Field Assistants for Terrestrial and Planetary Science
}

\author{
Larry A. Young \\ Edwin W. Aiken \\ Army/NASA Rotorcraft Division \\ Larry.A.Young@nasa.gov
}

Geoffrey A. Briggs

Center for Mars Exploration

\begin{abstract}
Field science in extreme terrestrial environments is often difficult and sometimes dangerous. Field seasons are also often short in duration. Robotic "field assistants," particularly small highly mobile rotary-wing platforms, have the potential to significantly augment a field season's scientific return on investment for geology and astrobiology researchers by providing an entirely new suite of sophisticated field tools. Robotic rotorcraft and other vertical lift planetary aerial vehicle also hold promise for supporting planetary science missions.
\end{abstract}

\section{TABLE OF CONTENTS}

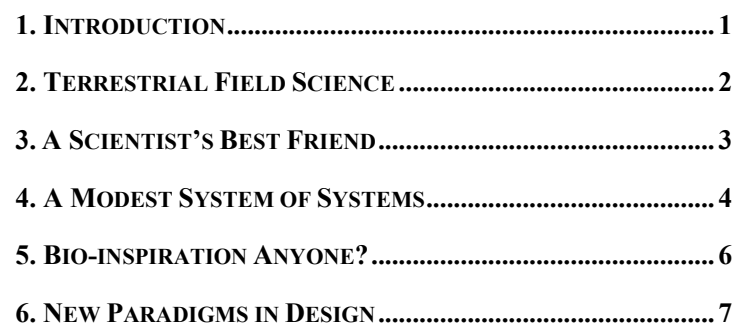

7. SEARCH \& Find MisSions AND SERENDIPITOUS SCIENCE 9

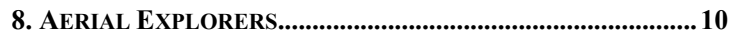

9. NOW AND THE NEAR-FUTURE ........................................... 12

CONCLUDING REMARKS......................................................... 12

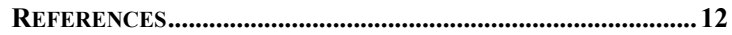

APPENDIX A - SRFA \& MARS ROTORCRAFT ......................... 14

APPENdix B - SRFA \& A STUdent Design COMPETITION17

\section{INTRODUCTION}

Small aerial robots are in a state of rapid development. The primary focus of most uninhabited aerial vehicle (UAV) and micro air vehicle research is currently directed to supporting future DOD missions. An alternate potential application for small autonomous aerial vehicles, particularly rotary-wing platforms, is their use in supporting terrestrial field science investigations in extreme environments, as well as potentially supporting Mars and other planetary science missions [1-14].

The "dirty, dull, dangerous," and difficult tasks that conventional UAVs and autonomous aerial vehicles are now being called into performing for military and public service applications hold true for applications supporting terrestrial field science. The mobility afforded by aerial robotic field assistants could potentially provide safe and routine access to sites that otherwise entail considerable effort on the part of field scientists (Fig. 1a-b). Further, the access and vantage provided by these robotic field assistants will have a significant leveraging effort on the magnitude and quality of the field season data gathering. The field assistants will interact with the field scientists in a productive manmachine partnership. Additionally, the robotic field assistants' potential ability to carry small science payloads, and/or acquire and carry small remote site samples, also emphasizes their potential utility in field science. It is these three attributes - the selective low-altitude imaging, the close scientist/robot interaction, and the equal design/operational emphasis of the aerial robot actions on the ground as well as in the air -- that make robotic field assistants unique in their design as compared to more conventional UAVs. 

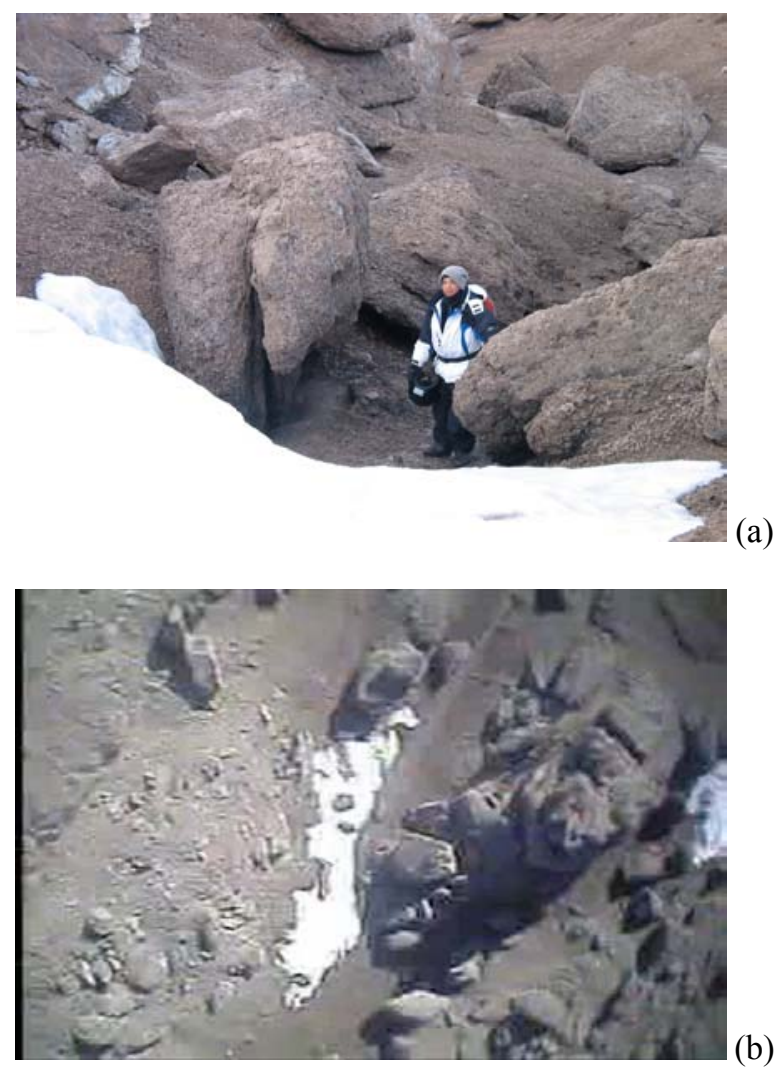

Fig. 1 - Gaining Access to Sites: (a) walking, climbing, and treking by ATV, or (b) making use of aerial robotic field assistants (downward-pointing aerial view)

Ongoing research at NASA Ames Research Center is examining the technical challenges of developing smart rotorcraft field assistants (SRFA) and their application to terrestrial field science -- refer to Fig. 2. The implications of this aerial robotic work are also being considered in the context of potential future planetary science missions employing vertical lift planetary aerial vehicles [2-9]. This work complements other ongoing research projects at NASA Ames on rotary-wing UAVs [42] and microrotorcraft [27].

Limited experimentation to date with simple radiocontrolled (RC) and/or automated surrogate aerial vehicles has just begun to demonstrate the potential of robotic field assistants. A number of unique technology challenges have been identified for the development of SRFA. The work discussed in this paper is the first preliminary steps in an important new area of research in robotics and rotary-wing vehicle systems.

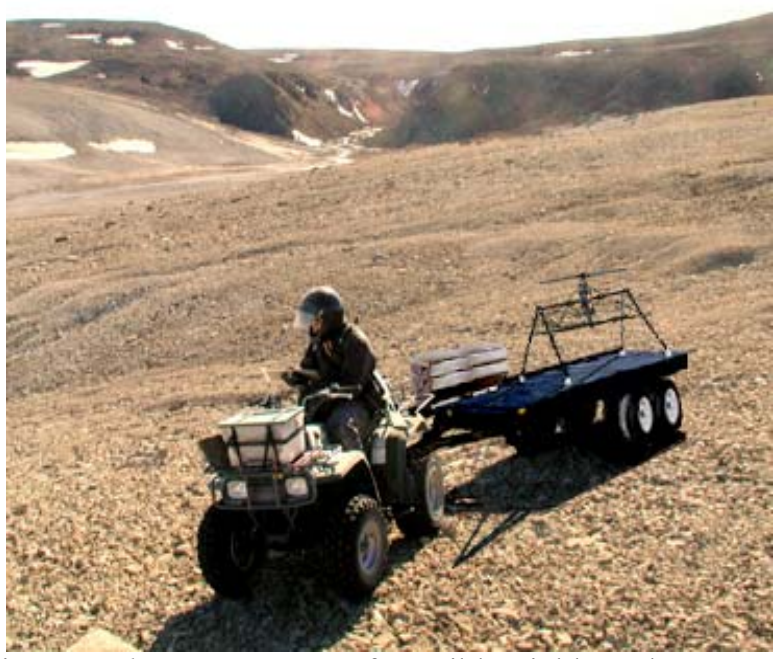

Fig. 2 -- Photo-composite of Possible Field Deployment of SRFA

There are unique demands - as compared to conventional UAV applications -- that will be placed upon robotic aerial field assistants for terrestrial science investigations in extreme environments. To better understand what these unique requirements might be, it is necessary to appreciate the types of field science being conducted by NASA and academia researchers [28-41].

\section{TERRESTRIAL FIELD SCIENCE}

Astrobiology and geological investigations at extreme environment field sites pose considerable challenges for researchers in terms of limited resources, including time, and productivity. The use of Mars-analog sites on Earth to support planetary science investigations has blossomed over the last several years. As such, it is increasingly important to consider empowering geologists and astrobiologists with automation tools and robotic systems that can assist them in their scientific endeavors. In many cases, the field scientist relies upon satellite and high-altitude aerial imagery to provide context for their on-the-ground field measurements and observations. For example, several small valley forming geological processes (sapping, glacial-melt waterrunoff, and glacial advance/retreat trough forming) in terrestrial sites have only been recognized in their analogous form on Mars by comparing satellite and aerial images between the two $[30,36,38,39]$. Not much work has been performed with low-altitude flights over Mars analog sites, the exceptions being [16, 22-24], but this type of aerial survey shows promise for future investigations.

Why small rotorcraft for these notional robotic field assistants versus other types of aerial vehicle configurations? For the same reason conventional manned helicopters are such flexible aerial platforms for terrestrial exploration and transportation: the ability to hover and fly at 
low-speeds and to take-off and land at unprepared remote sites.

It is also envisioned, though, that field scientists will ideally employ a suite of robotic assistants and automated tools to aid in the conduct of their research. Such a "system of systems" would in addition to SRFA include small fixedwing aerial explorers as well as robotic ground vehicles (rovers) to assist them.

Table 1 is an attempt for illustrative purposes to match typical science objectives at extreme environment field sites with brief assertions on how SRFA might be able to assist the field scientists. This list of science objectives is tailored with the Haughton Crater Mars-analog site in mind. However, as the primary objectives of most NASA extreme environment field science emphasizes geological and biological studies, this a fairly representative list for other potential analog sites.

Table 1 - Potential SRFA Contributions

\begin{tabular}{|c|c|}
\hline Science Objectives & SRFA Contributions \\
\hline $\begin{array}{l}\text { Characterization of } \\
\text { permafrost depth and density }\end{array}$ & $\begin{array}{l}\text { Multiple site acoustic sounding (speakers } \\
\text { on footpads) \& use of air-deployed } \\
\text { ground-penetrators }\end{array}$ \\
\hline $\begin{array}{l}\text { Snow melt, and/or } \\
\text { hydrodynamic, survey }\end{array}$ & $\begin{array}{l}\text { Deploy 3-5 "remote site" science stations } \\
\text { with a utility-class (Yamaha RMAX) } \\
\text { SRFA }\end{array}$ \\
\hline $\begin{array}{l}\text { Assess ongoing foreign flora } \\
\text { contamination of Devon } \\
\text { Island site }\end{array}$ & $\begin{array}{l}\text { Make assessments through a } \\
\text { combination of imaging, samples, and } \\
\text { snesor deployments }\end{array}$ \\
\hline $\begin{array}{lr}\text { Expand } & \text { upon } \\
\text { geology/mineralogy } & \text { surveys } \\
\text { of coastline } & \end{array}$ & 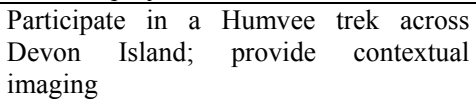 \\
\hline Assess glacier morphology & $\begin{array}{l}\text { Participate in a Humvee trek across } \\
\text { Devon Island; provide contextual } \\
\text { imaging; can deploy network of small } \\
\text { sensors to track glacial retreat } \\
\text { mechanisms }\end{array}$ \\
\hline $\begin{array}{l}\text { Continue assessment of } \\
\text { biology of impact craters }\end{array}$ & $\begin{array}{l}\text { Comprehensively map (quasi-3D with } \\
\text { stereoscopic image sets) Haughton } \\
\text { Crater interior }\end{array}$ \\
\hline $\begin{array}{l}\text { Improve understanding of } \\
\text { gully formation in valleys }\end{array}$ & $\begin{array}{l}\text { Perform high-resolution imaging of } \\
\text { gullies and air-deploy sensor packages }\end{array}$ \\
\hline $\begin{array}{l}\text { Understanding biochemical } \\
\text { and paleo-fossil implications } \\
\text { of hydrothermal vents }\end{array}$ & $\begin{array}{l}\text { Perform sampling missions using robotic } \\
\text { arms and devices }\end{array}$ \\
\hline $\begin{array}{lr}\text { Examine } & \text { the } \\
\text { ground/atmospheric heat } \\
\text { transfer mechanisms to } \\
\text { understand local climatology } \\
\text { during seasonal changes }\end{array}$ & $\begin{array}{l}\text { Use IR imaging device to perform night } \\
\text { surveys of Devon Island (non-summer- } \\
\text { season sensing/imaging; refer to } \\
\text { Appendix B) }\end{array}$ \\
\hline Polar bear sentry & \\
\hline
\end{tabular}

\section{A SCIENTIST'S BEST FRIEND}

Recent experience at Mars-analog sites, such as Haughton Crater, Devon Island, Canada, suggests that the use of small aerial vehicles can provide as a minimum a valuable "ondemand," personalized, aerial imagery capability [15-16]. However, such informal technology experiments and demonstrations only hint at what might be theoretically possible with SRFA robotic agents acting in quasipartnership with field scientists.

A representative sampling of field science being conducted at Mars-analog and/or terrestrial extreme environments can be found in [28-41]. A SRFA agent should, as a minimum, be able to assist in this general type of field science. One configuration, and size, of vehicle, though, is unlikely to meet all science objectives.

Smart rotorcraft field assistants can be categorized into a number of notional classes of vehicle, with unique function and roles, and attributes as noted in Table 2. A suite of vehicles and capabilities may need to be deployed during a given field season and/or research campaign in order to accomplish required goals.

For many of these applications and capabilities, SRFA will have more characteristics in common with notional micro air vehicles (MAVs) [49] - and micro-rotorcraft in particular [27] - than conventionally-sized UAVs and aerial vehicles. This is because SRFA and micro air vehicles both work at relatively low altitudes, in close proximity to people and objects on the ground, and depend upon close man/machine interaction to accomplish required goals. These systems embody/require a high level of personal utility. Correspondingly, many automation/operational models being developed for micro air vehicles will have great applicability to SRFA.

Manned aircraft have from their earliest inception supported terrestrial exploration and science. Recently fixed-wing UAVs (uninhabited aerial vehicles) and autonomous rotorcraft have also begun to play a part in terrestrial field science. Most of the precursor work using autonomous rotorcraft to conduct field science has focussed on volcanology [25-26].

Though proof-of-concept SRFA field testing at NASA Ames has primarily relied to-date upon small radiocontrolled helicopters (ranging from 1-6 kg in gross weight) a high-level of autonomy must be imbued into future SRFA platforms. Thus the aerial robot can be treated more as a true field tool than as flying vehicle. 
Table 2 - Different SRFA Classes, Their Functions/Roles, and Attributes

\begin{tabular}{|c|c|c|}
\hline Type/Class & Function/Role & Attributes \\
\hline $10-25 \mathrm{~kg}$ & $\begin{array}{l}\text { Close-Range } \\
\text { Surveyor }\end{array}$ & $\begin{array}{l}\text { - Carries onboard, perhaps modular and swappable, science instrumentation packages } \\
\text { - Carries \& deploys air-released probes and sensors } \\
\text { - Carries a suite of imaging cameras for detailed low-altitude surveys; as well as imagers for remote site (on the } \\
\text { ground) characterization }\end{array}$ \\
\hline $10-50 \mathrm{~kg}$ & Sampler & $\begin{array}{l}\text { - Acquire and transport soil/rock samples ranging from } 0.05 \text { to } 0.5 \mathrm{~kg} \\
\text { - Have an operational range of } 5-10 \mathrm{~km} \\
\text { - Robotic arms, actuators/effectors, or other devices to acquire soil and rock samples of at least } 100 \text { grams per sample } \\
\text { - Optional: limited ground mobility and/or carries robotic symbiotes to provide close-range ground access }\end{array}$ \\
\hline $50-100 \mathrm{~kg}$ & $\begin{array}{l}\text { Utility or Carrier } \\
\text { Platform }\end{array}$ & $\begin{array}{l}\text { - Must capable of carrying }>25 \% \text { gross-weight payloads } \\
\text { - Operational range of } 10-25 \mathrm{~km} \\
\text { - Initial trials can be conducted with NASA Ames Yamaha RMAX autonomous helicopter platforms [42] } \\
\text { - Semi-autonomous slung-load carrying capacity }\end{array}$ \\
\hline$>100 \mathrm{~kg}$ & $\begin{array}{l}\text { Long Range } \\
\text { and/or Endurance } \\
\text { Flyer }\end{array}$ & $\begin{array}{l}\text { - Must be capable of }>10 \% \text { gross-weight science payloads } \\
\text { - Operational range of }>100 \mathrm{~km} \text {; endurance of } 4-6 \text { hours } \\
\text { - Optional: ability to act as carrier platform for other aerial vehicles }\end{array}$ \\
\hline
\end{tabular}

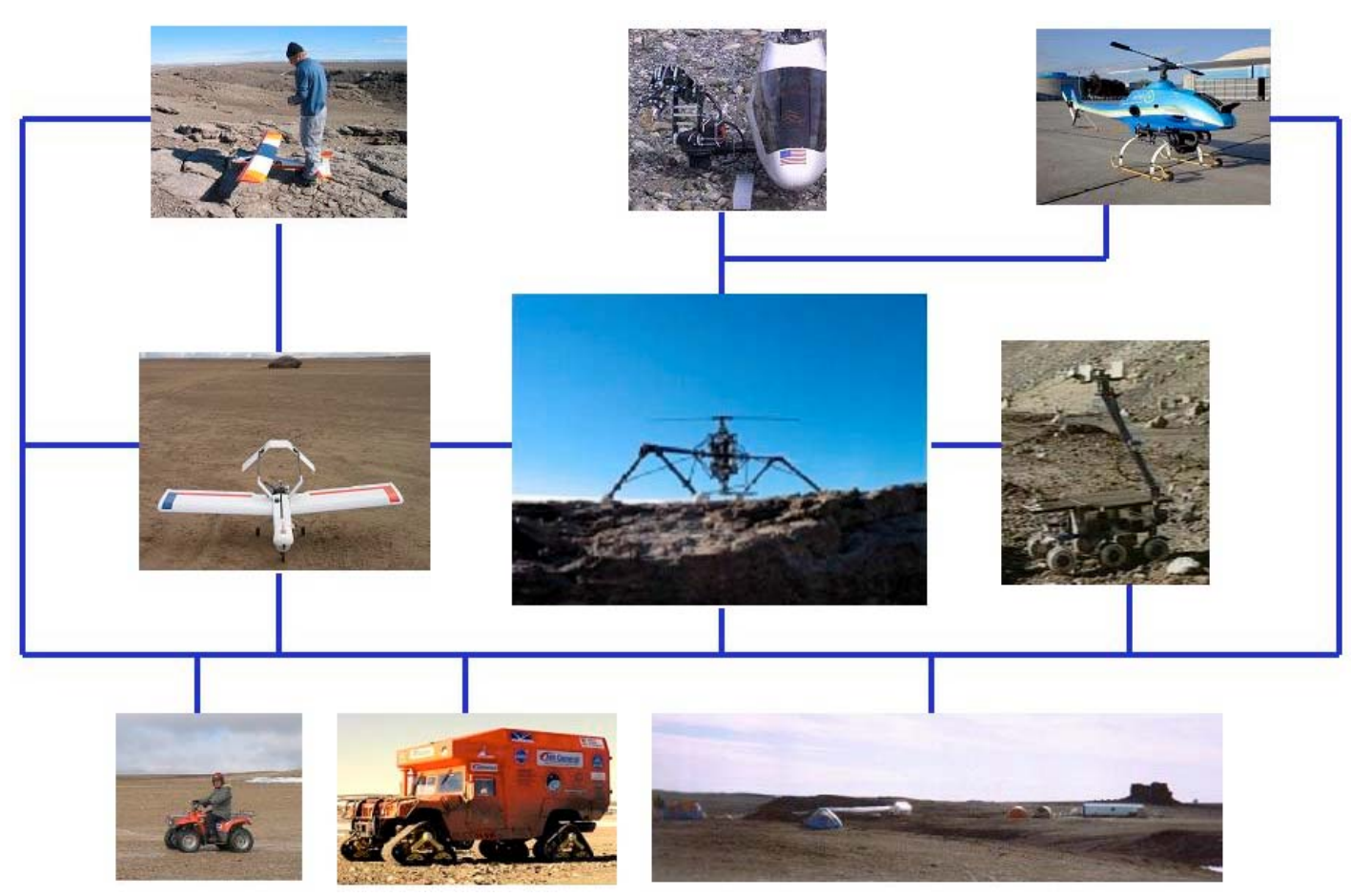

Fig. 3 - Notional System of Systems Including SRFA

\section{A MODEST SYSTEM OF SYSTEMS}

In order to achieve the above noted list of SRFA attributes (Table 2), it will likely be necessary to develop a network of robotic systems and automation tools to assist the terrestrial field scientist. Such a notional system of systems is illustrated in Fig. 3.
Such a system of systems approach yields an energetic symbiosis of field scientists, robotic systems, base camp equipment, and SRFA. Ultimately field seasons can perhaps be considerably extended through long-distance teleoperation of the SRFA in the field by researchers safely ensconced at the home institutions.

To date only elements of such a system of systems have undergone technology demonstrations at field sites. 
Several field demos have been conducted of rovers, and small fixed-wing UAVs [15-16], and rotary-wing platforms [22-24], but not in concert as a coordinated, comprehensive system, and not with the primary goal of actually performing science, but instead focusing on technology development issues. It must not be forgotten, though, that the objective of all this effort - this robotic system of systems -- is to perform efficient and robust science investigations. Such tools must allow the scientist to see what otherwise might not be seen (Fig. 4a-b).

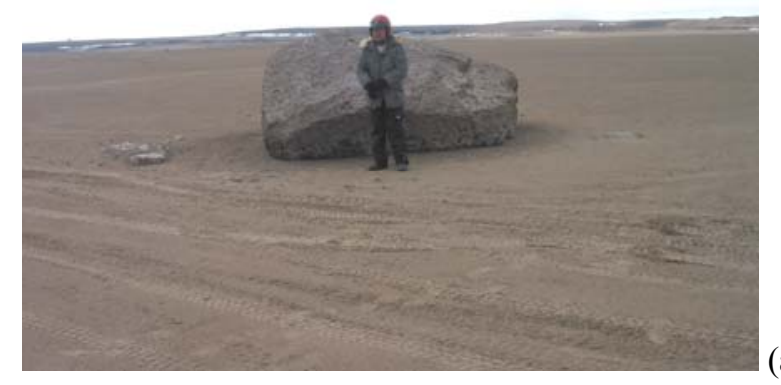

(a)

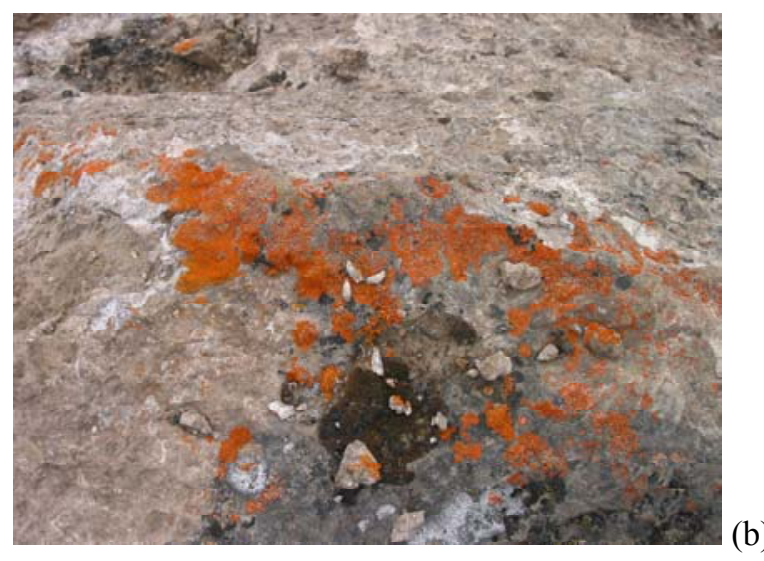

Fig. 4 - (a) Hamilton-Sundstrand Rock (Devon Island) and (b) the Arctic Lichen on the Top of It

Table 3 illustrates some of the potential system of systems elements that could be employed -- researchers, SRFA, other aerial vehicles, and other assets (robotic and otherwise) - and their roles and interactions/relationships. Table 3 is consistent with system of systems elements shown in Fig. 3. Not all elements (i.e. robots and assets) need necessarily be fielded. Inevitably this work touches upon intelligent systems concepts such as robotic colonies and ecologies [15, 19, and 20].
Table 3 - Example of System of Systems Elements, Roles, and Interactions/Relationships

\begin{tabular}{|c|c|c|}
\hline $\begin{array}{l}\text { System } \\
\text { Elements }\end{array}$ & Roles & Interactions \\
\hline $\begin{array}{l}\text { Simple } \mathrm{RC} \text {, } \\
\text { or remotely } \\
\text { piloted, aerial } \\
\text { vehicle }\end{array}$ & $\begin{array}{l}\text { Forward observation; } \\
\text { potentially expendable }\end{array}$ & $\begin{array}{l}\text { Line-of-sight direct down-link } \\
\text { to researcher, or relayed } \\
\text { through/to SRFA or } \\
\text { autonomous fixed-wing aerial } \\
\text { vehicle. }\end{array}$ \\
\hline $\begin{array}{l}\text { Autonomous } \\
\text { (fixed-wing) } \\
\text { Aerial } \\
\text { Vehicles } \\
\end{array}$ & $\begin{array}{l}\text { Long-range, } \text { higher- } \\
\text { altitude aerial survey; } \\
\text { sensor/drop-pod } \\
\text { deployment } \\
\end{array}$ & $\begin{array}{l}\text { Down- and up-link to SRFA } \\
\text { and/or } \\
\text { transported ground-stations }\end{array}$ \\
\hline Rover & $\begin{array}{l}\text { Detailed ground-level } \\
\text { observation and in-situ } \\
\text { analysis. Short to } \\
\text { moderate duration site } \\
\text { presence. }\end{array}$ & $\begin{array}{l}\text { Deployed to remote site by } \\
\text { ATV, Humvee, or potentially } \\
\text { by utility SRFA. Data and } \\
\text { imaging can be both down- and } \\
\text { up-linked through the aerial } \\
\text { assets/robots }\end{array}$ \\
\hline SRFA & $\begin{array}{l}\text { Three types shown in } \\
\text { Fig. 3: close-range } \\
\text { surveyor, sampler, and } \\
\text { utility SRFA }\end{array}$ & $\begin{array}{l}\text { Can work independently or in } \\
\text { conjunction with other robotic } \\
\text { assets. Relative strengths and } \\
\text { weakness of vehicles can be } \\
\text { traded against other fielded } \\
\text { assets available. Concurrent } \\
\text { operation of assets to maximize } \\
\text { efficiency. }\end{array}$ \\
\hline $\begin{array}{l}\text { ATV \& } \\
\text { Humvee }\end{array}$ & $\begin{array}{l}\text { Transport for } \\
\text { researcher and robotic } \\
\text { assets; ground-station; } \\
\text { initial analysis and } \\
\text { logging of data; } \\
\text { mounted } \\
\text { cameras/sensors } \\
\text { provide running } \\
\text { "ground-level" } \\
\text { information in addition } \\
\text { to, or in lieu of, rovers }\end{array}$ & $\begin{array}{l}\text { Control of short to mid-range } \\
\text { aerial assets, particularly the } \\
\text { RC or remotely-piloted } \\
\text { vehicles; initial collection and } \\
\text { collation of data and samples }\end{array}$ \\
\hline Base Camp & $\begin{array}{l}\text { Logistics support and } \\
\text { intermediate stage } \\
\text { analysis of data and } \\
\text { preparation }\end{array}$ & $\begin{array}{l}\text { Potential direct control of } \\
\text { longer-range robotic assets; } \\
\text { telecom to and from home } \\
\text { institutions; potential } \\
\text { automated support of extended } \\
\text { field season teleoperation of } \\
\text { robotic assets }\end{array}$ \\
\hline
\end{tabular}

One way Ames is attempting to advance this notional "system of systems" concept, as applied to scientific investigation of terrestrial extreme environments using aerial robots, is to co-sponsor a university student design competition (refer to Appendix B). This approach has worked quite well in the past as applied to vertical lift planetary aerial vehicles [10-13 and 50] and other emerging design concepts. 


\section{BIO-INSPIRATION ANYONE?}

SRFA flight control, navigation, and overall autonomy may benefit from emergent bio-inspired technologies for robotic and aerial vehicle control. Bio-inspiration for such vehicles can take many forms. Past work has focused on bioinspired vision systems [17] and autonomous aerial vehicle roles, flight behaviors, and decision-making processes [1821]. Figure 5 shows the preliminary simulation results of a terrain following algorithm for an autonomous aerial vehicle [15] (in this case following an increasing terrain elevation gradient and then doubling back when cresting over the highest point).

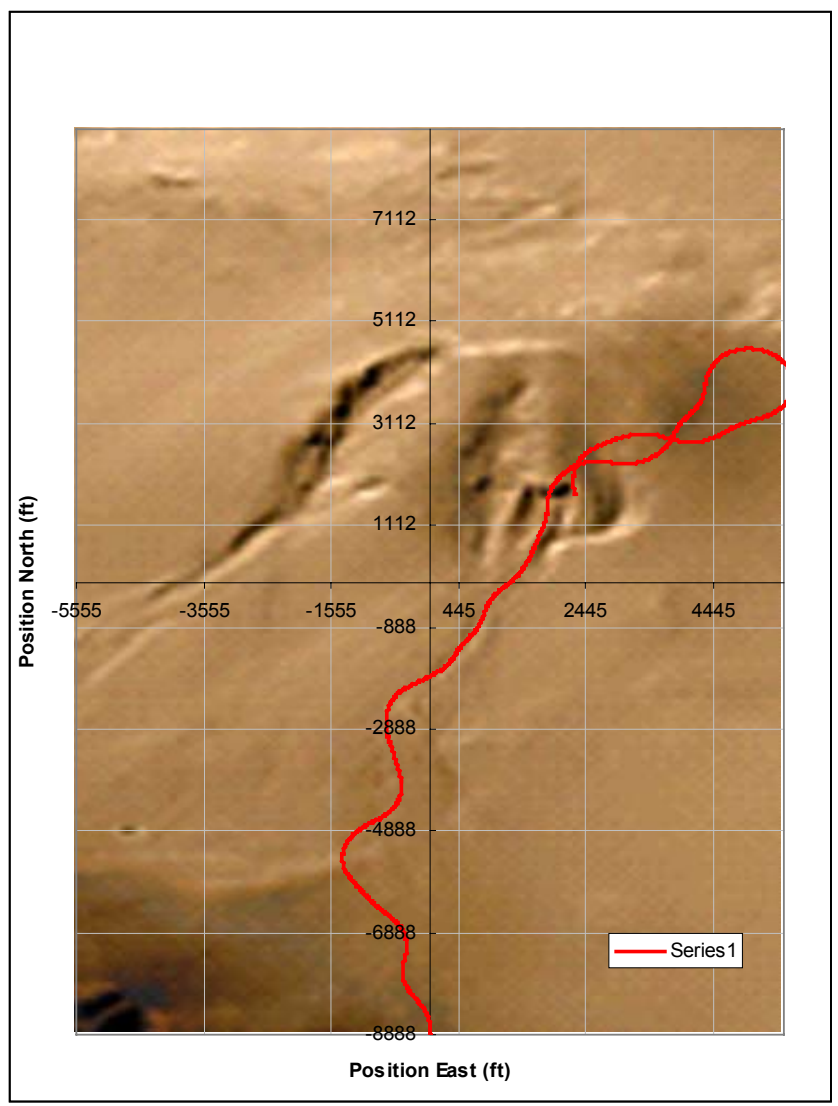

Fig. 5 - Simple Bio-inspired Aerial Vehicle Terrain Following

As discussed previously, SRFA will need to act in concert with other robotic systems and automation tools. This will form almost a robotic symbiosis between systems. Simple field demos at Ames have begun to examine the interdependencies of such robotic symbiosis implicit in a system of systems (Fig. 6). This is an area of great importance for not only SRFA and robotic field assistants for terrestrial field science, but for many other applications as well.

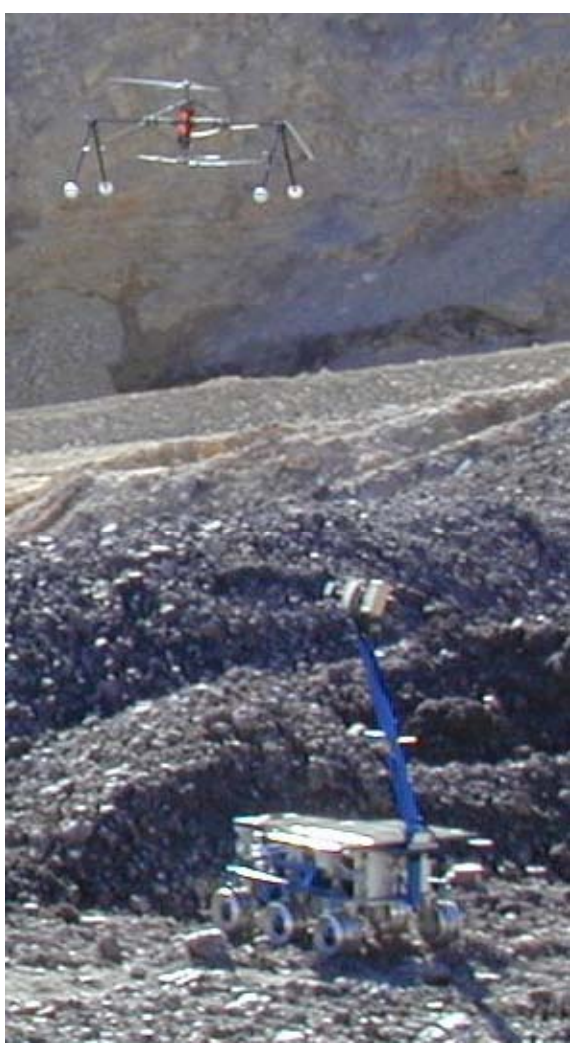

Fig. 6 - Robotic Symbiosis

Proof-of-concept work has also been pursued at NASA Ames looking into extending the capabilities of SRFA-type platforms from simple imaging to soil/rock sampling tasks (Fig. 7). Traditionally, rotorcraft designers concern themselves with only how well, how efficiently, an aircraft flies. The whole concept of providing a robotic helicopter with "reach," with "grasp" while on the ground at a remote site is somewhat an alien concept. And yet, this ability would be a tremendous enhancing capability for a SRFA.

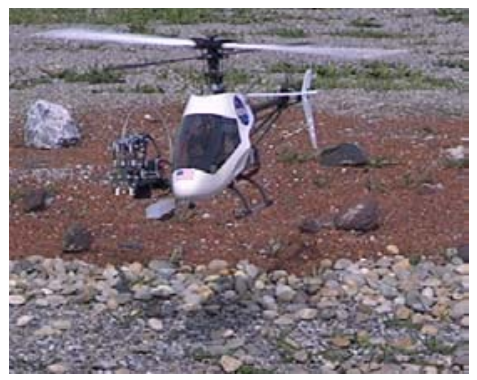

Fig. 7 -Robotic Arms \& Rotary-Wings

Bio-inspiration work at Ames has also led to an increased emphasis on aerial explorers and SRFA performing mission tasks such as the air-deployment of camera/sensor drop probes from aerial explorers - drawing on concepts loosely based on biological reproduction strategies (Fig. 8). These probes and robotic devices deployed by the SRFA then 
consequently become additional elements of the system of systems - forming robot ecology [19-20] -- used to study the field site. In this manner, drawing upon some of the concepts outlined in Table 4, the utility of SRFA, and other aerial explorers, can be greatly enhanced beyond the simple act of aerial imaging surveys.
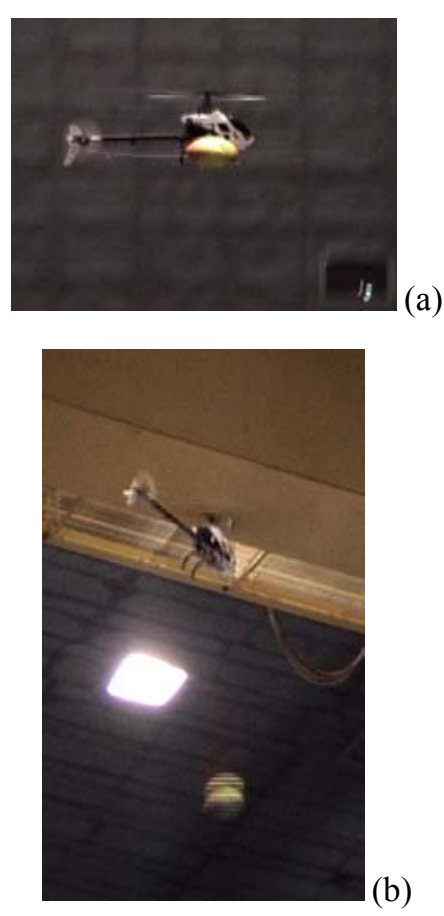

Fig. 8 --Dissemination/Distribution: (a) carrying an imaging/sensor drop probe and (b) probe release

Bio-inspiration has potentially an important role in engineering innovation. It remains to be seen what this emerging field of study can fully realize in terms of new technological capabilities and applications. It has already enabled, though, a re-conceptualization at NASA Ames of the "helicopter as robot."

\section{NEW PARADIGMS IN DESIGN}

The SRFA concept requires a new design paradigm as compared to conventional aircraft and UAV design. The proof-of-concept exercise of grafting/integrating a robotic arm to an RC helicopter is just one radical example of this new paradigm. Design and integration of other, new and challenging, onboard equipment/sub-systems (Table 4) will also be required for a successful stable of SRFA tools for the field scientist.

Ruggedization of equipment, in general, and the SRFA, in particular, is essential for efficient and effective use of these platforms under the extreme environment conditions under which they will operate. In past field demo campaigns of robotic hardware at the Haughton Crater Mars-analog site, productivity has been severely hampered by operating hardware that was not adequately prepared to endure the frequent harsh conditions demanded on them - including rain, cold temperatures, and high winds.

Table 4 - Types of SRFA Onboard and Ground Auxiliary Equipment

\begin{tabular}{|c|c|}
\hline Equipment & Purpose \\
\hline \multicolumn{2}{|l|}{ Onboard } \\
\hline $\begin{array}{l}\text { Simple snatch and grab sampling } \\
\text { devices on landing gear footpads }\end{array}$ & \begin{tabular}{|lll} 
Mineralogical & and/or & biological \\
samples from difficult to access \\
sites
\end{tabular} \\
\hline $\begin{array}{l}\text { Robotic arms and other more } \\
\text { sophisticated effectors }\end{array}$ & See above \\
\hline Air-deployed ground penetrators & $\begin{array}{l}\text { Just-below ground surface } \\
\text { characterization }\end{array}$ \\
\hline $\begin{array}{l}\text { "Harpoon" samplers (w. \& w.o. } \\
\text { reelable tethers) }\end{array}$ & $\begin{array}{l}\text { Increasing the "reach" of SRFA } \\
\text { while on-ground }\end{array}$ \\
\hline $\begin{array}{l}\text { Air-deployed drop-probes }[16,18] ; \\
\text { drop-probe(s) } \\
\text { cameras, could contain } \\
\text { environmental } \\
\text { chemical/biological chip-arrays, etc }\end{array}$ & $\begin{array}{l}\text { Efficient distribution/dissemination } \\
\text { of sensor networks; "calibration" of } \\
\text { aerial imagery with descent and } \\
\text { ground images }\end{array}$ \\
\hline $\begin{array}{l}\text { Air-deployed gliders, or } \\
\text { autorotating "samara seed" imaging } \\
\text { platforms [18] }\end{array}$ & $\begin{array}{l}\text { Increasing efficiency of science } \\
\text { missions by deployment of } \\
\text { secondary agents to SRFA }\end{array}$ \\
\hline $\begin{array}{l}\text { Air-deployed, or ground-released, } \\
\text { micro-rovers (perhaps ball-shaped } \\
\text { robots [43-45]) }\end{array}$ & See above \\
\hline Air-deployed “tetherbot" [16] & See above \\
\hline $\begin{array}{l}\text { Ground-deployable ("slung load") } \\
\text { science "remote station" payloads }\end{array}$ & $\begin{array}{l}\text { Building longer term science } \\
\text { infrastructure }\end{array}$ \\
\hline \multicolumn{2}{|c|}{\begin{tabular}{l|l} 
Ground Auxiliary & \\
\end{tabular}} \\
\hline $\begin{array}{l}\text { Transport, launch, and recovery } \\
\text { equipment }\end{array}$ & Enabling requirement \\
\hline Recharging/refueling equipment & Enhancing requirement \\
\hline $\begin{array}{l}\text { Ground station and operator } \\
\text { interface }\end{array}$ & Enabling requirement \\
\hline
\end{tabular}

Though the transport and deployment equipment for SRFA will be considerably less challenging than that of a Mars aerial vehicle, it is still presents interesting problems. Transport of SRFA assets will have to employ ATV's, or possibly a tracked Humvee. Equipment by necessity will have to be lightweight and of small package. Assembly and checkout of the vehicle will need to be kept to a minimum.

One innovative approach for SRFA transport and deployment is to develop a hybrid mothership/drone aerial vehicle (Fig. 9). This innovative concept integrates a medium altitude and long endurance/range flight platform (Aerial Surveyor 'flying-wing' mothership) with multiple deployable low-altitude close-support coaxial rotorcraft UAVs as 'drones.' The mothership contains multiple propulsion modules (coaxial proprotors serving doubleduty); these propulsion modules can separate from the main vehicle over a target area of interest, at high-altitudes, and can be dropped from the surveyor 'mothership' like a 
munitions 'store.' These propulsion modules -- now acting as independent rotary-wing UAVs/drones -- autorotate upon release from the mothership and descend to low-altitudes, whereupon they achieve full thrust and power and act as coaxial helicopters. The coaxial helicopter drones survey targeted areas of interest in a distributed pattern at lowaltitude and low-speed and report to main base directly, or have telecommunications relayed through the partiallypowered mothership circling overhead.

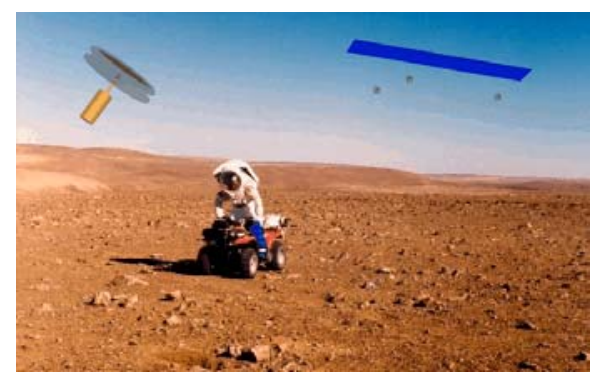

Fig. 9 - Aerial Surveyor: Alternate Approach for Deploying SRFA (Foreground Image Courtesy of P. Lee, Mars \& SETI Institutes)

Alternatively, the on-the-ground mobility, or access, of a SRFA has to be carefully considered. What if the rock/soil sample of choice is not in the immediate vicinity, "footprint," of the SRFA? How then will the sample be acquired, the micro-image be taken, or the science probe or instrumentation placed? This is a difficult design problem to pose. Hybrid vehicles that have an element of ground mobility in addition to their aerial mobility may need to be considered for field science applications (Fig. 10a-c). Or alternatively, as noted above, a robotic symbiosis between the SRFA and an assortment of auxiliary robotic devices transported into the field site may be required in order to meet all field campaign requirements.

One design solution likely will not meet all requirements. It is anticipated that a whole range of SRFA agent configurations might be required to accomplish the ambitious field science campaigns of the future.

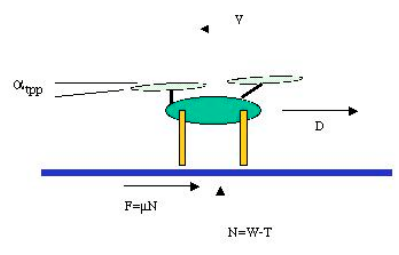

(a)

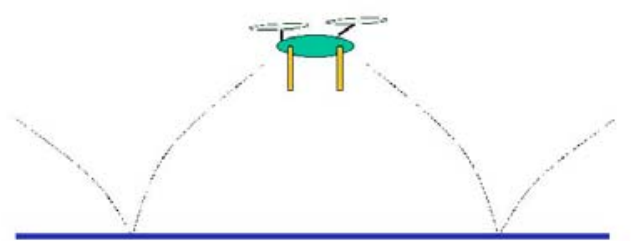

(b)

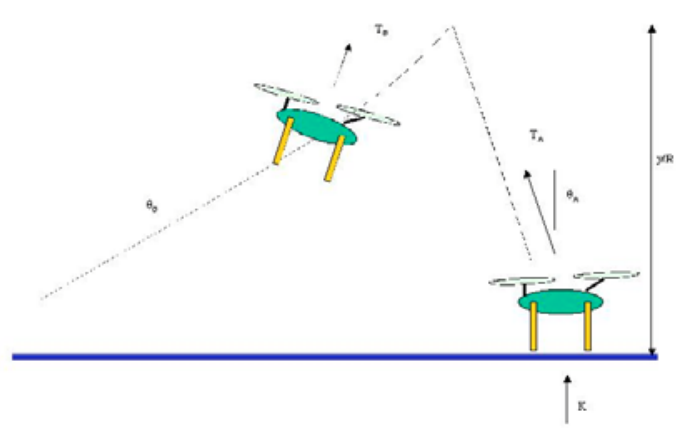

(c)

Fig. 10 - Ground Mobility for SRFA: (a) skim, (b) skip, and (c) jumping required in addition to flight?

Though preliminary work has shown the promise of SRFA as simple radio-controlled devices, the real pay-off for their use will come when high levels of autonomous system technology has been implemented on them. (RC piloting is a specialized skill and one not easily acquired by the typical scientist. Further the scientist should ideally be doing science and not flying RC aircraft.) However, automation does not automatically confer a reduction in the logistics necessary to conduct field science with these platforms. For example, a simple RC-controlled aerial vehicle currently takes two people to perform low-altitude aerial imaging: one to operate the vehicle and another to operate the wireless video receiver/recorder equipment. A quasi-production small autonomous aerial vehicle can require between three to four people. Refer to Fig. 11 and [16] for an illustrative example of a fixed-wing UAV campaign, or [42] for a rotary-wing platform.

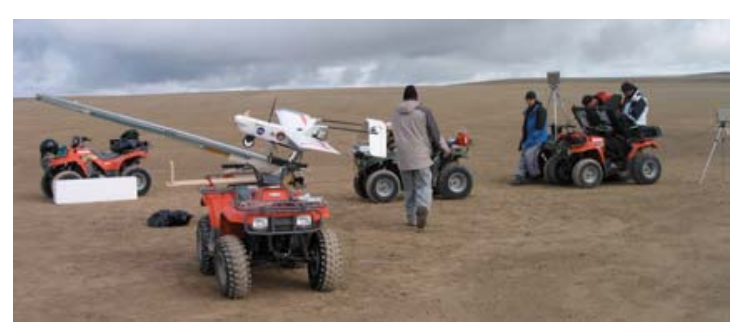

Fig. 11 - Typical Current Technology Support/Logistics Required 


\section{SEARCH \& FIND MISSIONS AND SERENDIPITOUS SCIENCE}

Science is the process of discovery. As a semi-autonomous agent/tool for discovery, a SRFA's "intelligence" must be tailored to optimize that process (Fig. 12). Therefore, equal emphasis must be placed on the SRFA science application software as is applied to the flight/mission autonomous control software. Further, there must be an integrated approach to linking the science software package, and associated sensors, with the flight/navigation software and its guidance and safety-of-flight instrumentation.
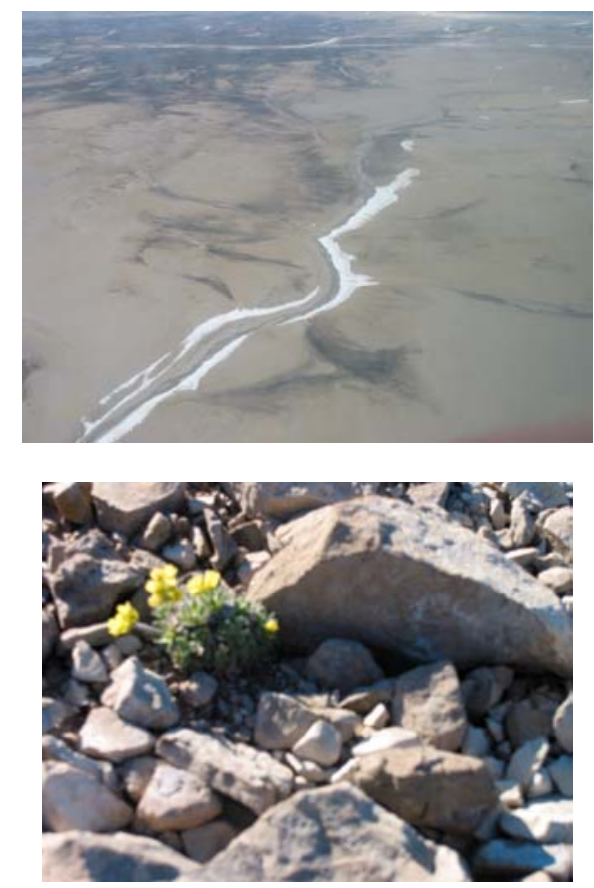

Fig. 12 - Searching for Subtle Signs of Life in a Barren Landscape From the Air

Oftentimes, field science in terrestrial extreme environments is also the science of opportunity. Meticulous, detailed, advance planning may radically be revised to compensate for weather changes, resource limitations, and chance discoveries. Mission flexibility is essential to provide the field researcher an appropriate level of utility. Again, the enhanced access and vantage provided by SRFA can potentially leverage significantly the scientific return on investment.

Figure 13 is illustrative of how aerial robotic field assistants can provide unique low-altitude imaging perspectives for scientists. Imaging data from SRFA and other field assistants can be post-processed and interpreted to yield image mosaics and quasi-three-dimensional terrain mappings. Re-tasking and subsequent flyovers of SRFA could be targeted at hard to access locations to examine at high-resolution and high detail rock outcroppings, (arctic) flora, and other features of interest.
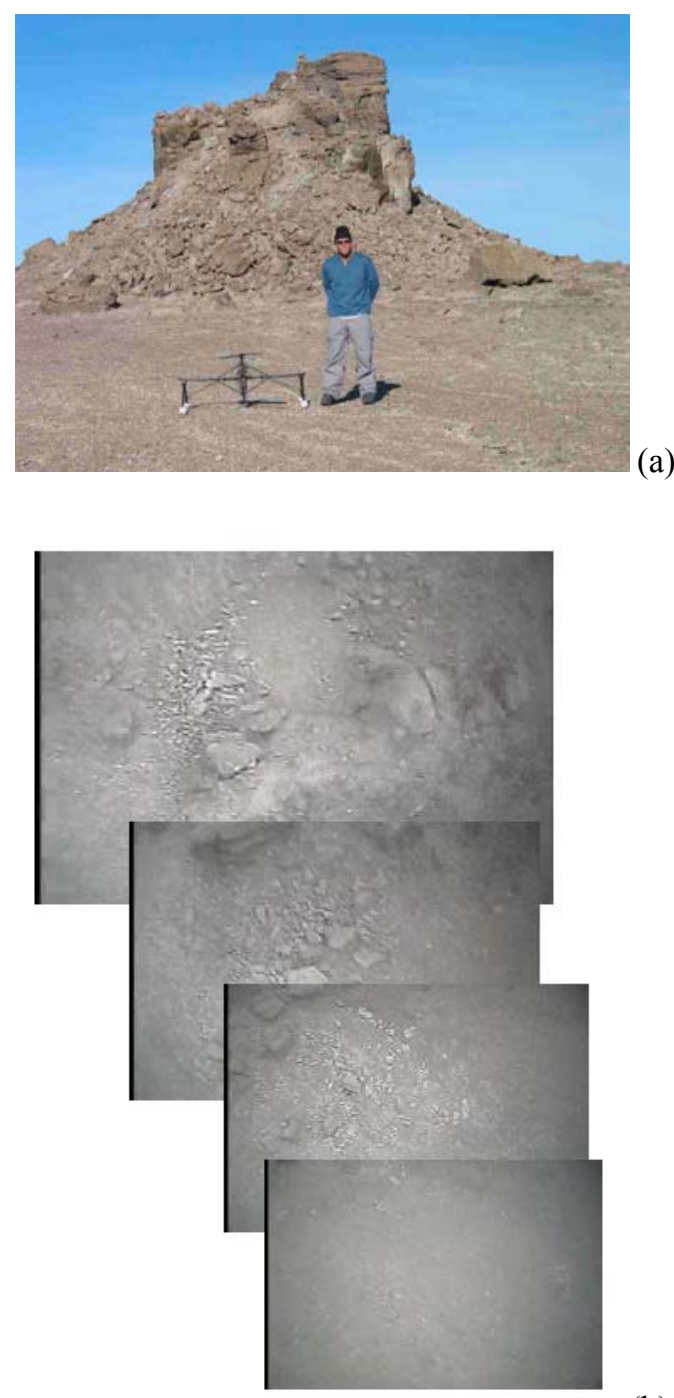

(b)

Fig. 13 - Aerial Imaging from Aerial Explorers (a) view from the ground and (b) from the air

Figures 14-16 present three different examples of operational scenarios that a SRFA might be tasked to perform in order to aid field scientists in the conduct of their research.

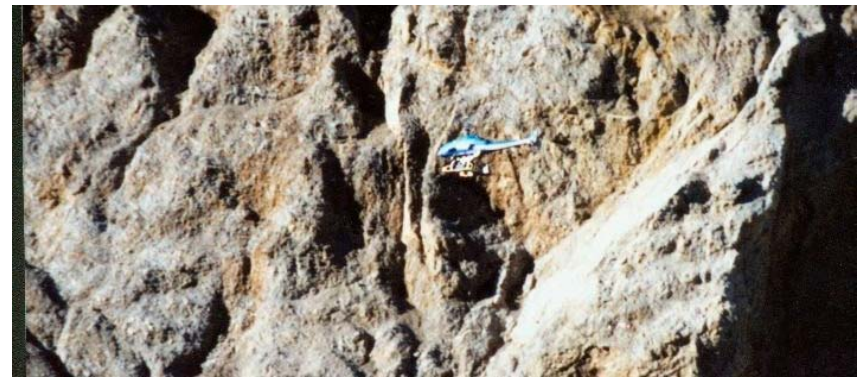

Fig. 14 - Operational Scenario \#1: Access to Elevated, or Otherwise, Hazardous Terrain 
Table 5 - Examples of Operational Scenario Tasking

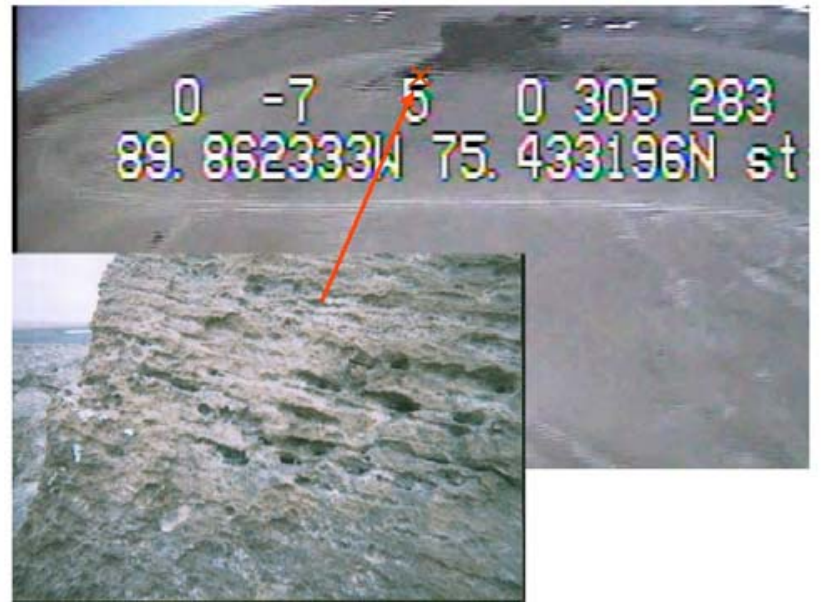

Fig. 15 - Operational Scenario \#2: Characterize Site to Provide Context for Specimen Collecting

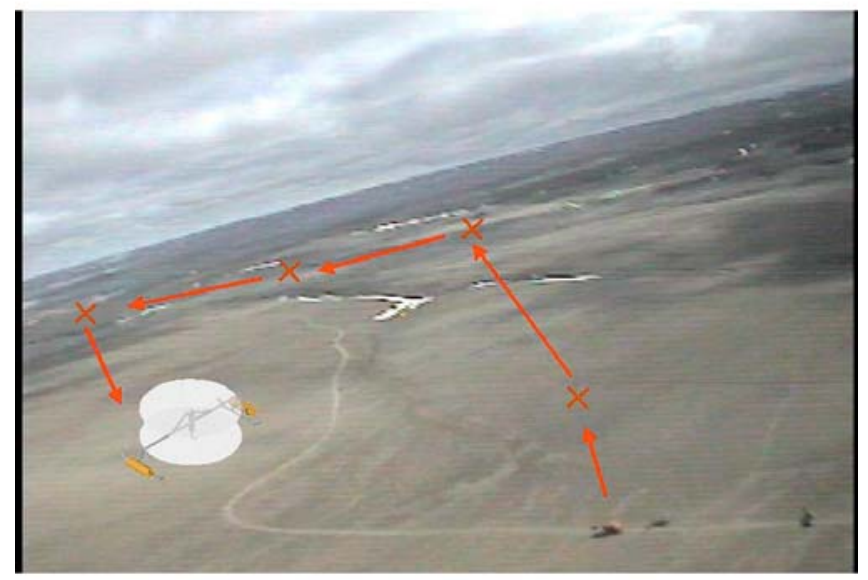

Fig. 16 - Operational Scenario \#3: Scouting or Expanding Data Gathering Capability

Table 5 is a representative list of tasks that SRFA might execute as a part of each of the three operational scenarios shown in Figs. 14-16. The definition of these operational scenarios and SRFA tasks benefit from experience gained in participating in the 2002 and 2003 summer field seasons of the NASA Haughton Mars Project. Other field sites might have different requirements and constraints on the research being conducted by scientists - and supported by SRFA -but Table 5 is still likely a good subset of the tasks and scenarios an efficient/effective SRFA will need to be able to accomplish.

\begin{tabular}{|c|c|}
\hline $\begin{array}{l}\text { Operational } \\
\text { Scenario }\end{array}$ & Sample List of Tasking \\
\hline $\begin{array}{l}\# 1 \text { - Access } \\
\text { to Elevated, } \\
\text { or Otherwise, } \\
\text { Hazardous } \\
\text { Terrain }\end{array}$ & $\begin{array}{l}\text { A. Commanded to take-off and hover at a specified } \\
\text { altitude at the launch/recovery area } \\
\text { B. Next rotates about vertical axis and acquires a } \\
\text { panoramic image of the immediate area } \\
\text { C. Commanded into forward-flight to approach terrain } \\
\text { feature of interest (steep rock formations, crater rim, } \\
\text { hydrothermal vents, etc.); climbs to adequate altitude to } \\
\text { comfortably clear any terrain obstacles of concern } \\
\text { D. Performs either circling overflight over a discrete } \\
\text { terrain feature of interest (such as a rock formations of } \\
\text { vents), or skirts along a terrain boundary (as in the case of } \\
\text { a valley or ridgeline) } \\
\text { E. Completing survey, commanded to critical priority site } \\
\text { and a vertical landing is attempted or sensor/probes are } \\
\text { deployed } \\
\text { F. Sampling, ground-level imaging, or sensor/probe } \\
\text { deployment is completed and SRFA is recalled to } \\
\text { launch/recovery site }\end{array}$ \\
\hline $\begin{array}{l}\# 2 \\
\text { Characterize } \\
\text { Site to } \\
\text { Provide } \\
\text { Context for } \\
\text { Specimen } \\
\text { Collecting }\end{array}$ & $\begin{array}{l}\text { A. A field scientist acquires several soil/rock or biological } \\
\text { samples by hand; GPS coordinates and photographic } \\
\text { images are taken to provide context and ground-truth } \\
\text { B. The researcher launches a close-range survey SRFA } \\
\text { from near his ATV, after completing his sample taking, } \\
\text { but before leaving the site } \\
\text { C. The SRFA is guided/commanded to each location } \\
\text { within the site where samples were taken. Both landscape } \\
\text { and panoramic images are taken to provide context - at an } \\
\text { elevated altitude/perspective - for where the samples were } \\
\text { acquired } \\
\text { D. Upon the SRFA returning to the launch/recovery point, } \\
\text { the downloaded images can be post-processed to aid the } \\
\text { scientist in interpreting/understanding the data from the } \\
\text { samples }\end{array}$ \\
\hline $\begin{array}{l}\text { \#3 - Scouting } \\
\text { or Expanding } \\
\text { Data } \\
\text { Gathering } \\
\text { Capability }\end{array}$ & $\begin{array}{l}\text { A. Expeditionary ATV/Humvee trek is initiated } \\
\text { B. Periodically, with rest stops, a short-range SRFA is } \\
\text { launched near, or from, the convoy. } \\
\text { C. The SRFA aerial survey images the landscape in } \\
\text { directions lateral to, and forward of, the convoy } \\
\text { D. Survey images used to provide forward scouting } \\
\text { information for the trek convoy; also documents territory } \\
\text { that would otherwise would not be seen line-of-sight } \\
\text { during the trek. } \\
\text { E. During pitching of camp for the night, a longer-range, } \\
\text { higher-altitude SRFA or autonomous fixed-wing aerial } \\
\text { vehicle could be launched; trek mission decisions as to } \\
\text { identifying sites for detailed investigation could be made } \\
\text { on the basis of long-range survey info }\end{array}$ \\
\hline
\end{tabular}

\section{AERIAL EXPLORERS}

Planetary aerial vehicles would provide an element of threedimensional mobility that would greatly enhance the exploration of other planets. Such aerial explorer mobility - particularly with vertical lift aerial vehicles -- would allow investigation of terrain features of interest that were inaccessible by any other means. It is especially crucial to insure that proposed aerial explorer missions are not seen as mere technology demonstrations but as the best tools available to meet the objectives of a science-driven mission. 
Most discussion regarding planetary aerial explorers has focused on Mars airplanes or balloons. This is unfortunate, to some degree, for two reasons. First, no one single vehicle type, or design configuration for that matter, is going to meet all science objectives. Certain vehicle types will be better for certain missions and science objectives. Multiple missions using multiple vehicle types might well be required to conduct the comprehensive research dictated by the planetary science community. Second, there are many planetary bodies in our Solar System, in addition to Mars, where aerial explorers might be used to great advantage. Scientific investigation of Venus, Titan, and the outer gas giant planets could all benefit from the use of aerial explorers, as well.

Lessons learned from SRFA development and operation on Earth will ideally one day also find their way into the development of planetary aerial vehicles for Mars exploration and other planetary bodies (Fig. 17). Concurrent with the SRFA work, research continues to be conducted at a modest level at NASA Ames on vertical lift planetary aerial vehicles. Appendix A discusses the current status of Mars rotorcraft research at Ames.

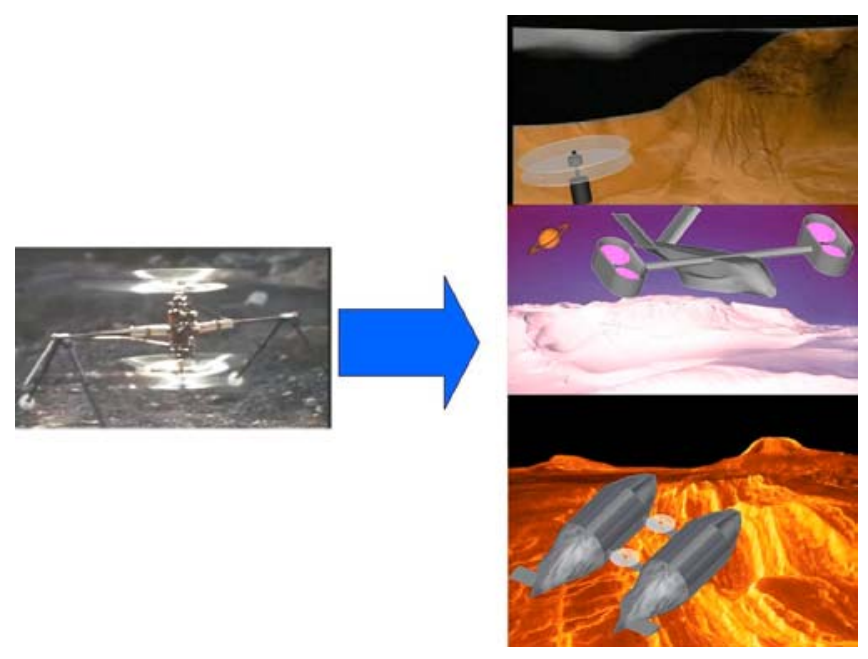

Fig. 17 - From SRFA to Vertical Lift Planetary Aerial Vehicles

From a technological perspective, there are many dual-use aspects between required SRFA technologies and those needed for Mars rotorcraft. Table 6 summarizes some of these dual-use, or unique, technologies. Ideally, to conserve resources, emphasis for the SRFA and Mars rotorcraft development efforts should be placed on the highest priority dual-use technologies.
Table 6 -- Dual-Use and Unique Technologies for SRFA and Mars Rotorcraft

\begin{tabular}{|c|c|}
\hline Technology & Dual-Use or Unique \\
\hline Automation & $\begin{array}{l}\text { Dual-Use (though Mars application has the more } \\
\text { stringent requirements); additionally } \\
\text { electronics/processors for space applications are } \\
\text { subject to radiation effects/upsets }\end{array}$ \\
\hline $\begin{array}{l}\text { Rotor } \\
\text { Aerodynamics }\end{array}$ & $\begin{array}{l}\text { Partial dual-use. Both Mars rotorcraft and SRFA } \\
\text { require low-Reynolds rotors; however, the Mars } \\
\text { rotorcraft rotors will be subject to compressible } \\
\text { flow effects in addition to the low-Reynolds } \\
\text { airfoil/rotor characteristics. }\end{array}$ \\
\hline Power/Propulsion & $\begin{array}{l}\text { Partial dual-use. Ideally SRFA and Mars rotorcraft } \\
\text { would both employ electric propulsion. Therefore } \\
\text { advances in power electronics, batteries, and fuel- } \\
\text { cells would benefit both. But, if need be, SRFA } \\
\text { could be based upon internal combustion engines. }\end{array}$ \\
\hline $\begin{array}{l}\text { Robotic } \\
\text { Actuators/Effectors }\end{array}$ & Dual-use \\
\hline $\begin{array}{lr}\text { Transport } & \text { and } \\
\text { Deployment } & \text { of } \\
\text { Sensors/Probes } & \end{array}$ & Dual-use \\
\hline $\begin{array}{l}\text { Ultra-lightweight } \\
\text { Structures \& } \\
\text { dynamics }\end{array}$ & Unique to Mars rotorcraft \\
\hline $\begin{array}{l}\text { Deployable blades } \\
\text { and folding and/or } \\
\text { telescoping } \\
\text { structures }\end{array}$ & Unique to Mars Rotorcraft \\
\hline $\begin{array}{l}\text { Thermal } \\
\text { management }\end{array}$ & $\begin{array}{l}\text { Partial unique to Mars rotorcraft. Temperature } \\
\text { extremes for Mars are far worse than any extreme } \\
\text { environment on Earth }\end{array}$ \\
\hline Navigation & $\begin{array}{l}\text { Partial dual-use. SRFA can generally rely on GPS } \\
\text { for navigation, though satellite coverage can be } \\
\text { spotty in the arctic and Antarctic regions. GPS } \\
\text { navigation is not an option for Mars rotorcraft; } \\
\text { other forms of navigation, such as vision-based } \\
\text { systems, will be required. Nonetheless, even } \\
\text { terrestrial applications could potentially benefit } \\
\text { from the addition/inclusion of non-GPS navigation } \\
\text { strategies }\end{array}$ \\
\hline $\begin{array}{l}\text { Automated } \\
\text { handling } \\
\text { Servicing }\end{array}$ & $\begin{array}{l}\text { Unique to Mars rotorcraft. The exception might be } \\
\text { specialized terrestrial applications such as the } \mathrm{TE}^{3} \\
\text { mission as noted in Appendix B. }\end{array}$ \\
\hline
\end{tabular}

One of the advantages of terrestrial applications of robotic aerial explorers, such as SRFA, is that GPS navigation can be used for these vehicles -- planetary aerial vehicles have no such luxury. Alternate navigation/guidance techniques, such as those inspired from biology [17], will need to be used for aerial explorers on other planets. 


\section{NOW AND THE NEAR-FUTURE}

Future efforts will continue to examine the ability of SRFA to enhance the scientific return on investment in the field, as well as leverage this proof-of-concept terrestrial work into the ongoing technology development for Mars rotorcraft (Fig. 18). For example, a NASA "Vision Mission" proposal has been submitted wherein a Mobile Science Laboratory (MSL) rover platform would be augmented by a Mars rotorcraft.

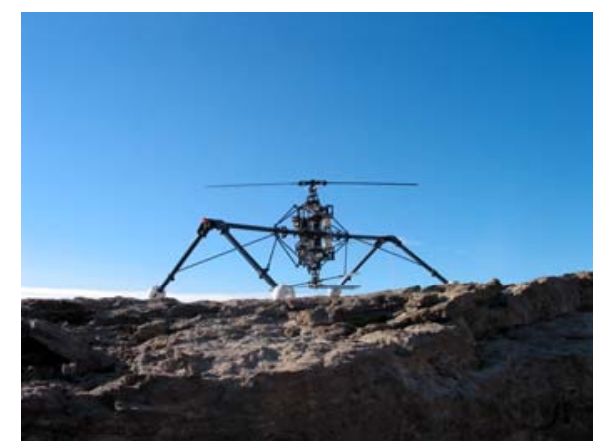

Fig. 18 - Transitioning from the Proof-of-Concept to a Viable Smart Rotorcraft Field Assistant

Finally, a Minority University Education and Research Program (MUREP) student design competition is currently in the planning stages. This competition will be on the topic of a Terrestrial Extreme Environment Explorer $\left(\mathrm{TE}^{3}\right)$ - an aerial robotic science field assistant system of systems similar to what has been discussed in this paper. This MUREP $\mathrm{TE}^{3}$ competition follows a successful AHS (American Helicopter Society) student design competition on the topic of Mars rotorcraft (2000) [10-13] and an earlier MUREP competition on the topic of a Titan vertical lift aerial vehicle (2003) [50]. A draft version of the proposed $\mathrm{TE}^{3}$ competition RFP (request for proposal) is summarized in Appendix B.

\section{CONCLUDING REMARKS}

Smart Rotorcraft Field Assistants may one day provide an important enhancing capability for terrestrial field scientists. Scientists, robotic systems, automation tools, and SRFA working together will form a unique symbiosis in performing field science. Some preliminary work by NASA Ames has begun to address some of the technology challenges developing aerial robotic field assistants. Finally, proof-of-concept work from the SRFA investigations has direct application to planetary aerial vehicles, particularly Mars rotorcraft.

\section{ACKNOWLEDGMENTS}

The authors gratefully acknowledge the many people who are contributing to the development and demonstration of robotic helicopters for field science investigations for both terrestrial and planetary science applications. Among these many fellow co-investigators and contributors are: Dr. Pascal Lee, Principal Investigator of the Haughton Mars Project, of the SETI and Mars Institutes; Dr. Virginia Gulick, SETI Institute; Mathew Whalley, Project Manager of the Autonomous Rotorcraft project, U.S. Army/NASA Rotorcraft Division; Greg Pisanich, Manager of the Intelligent Aerial Vehicle project, QSS Group, Inc., Computational Sciences Division, NASA Ames; Corey Ippolito, QSS Group, Inc, Computational Sciences Division; Ray Demblewski, College of San Mateo; Jose Navarrete, Rice University.

\section{REFERENCES}

1. Aiken, E.W., Ormiston, R.A., and Young, L.A., "Future Directions in Rotorcraft Technology at Ames Research Center," $56^{\text {th }}$ Annual Forum of the American Helicopter Society, International, Virginia Beach, VA, May 2-4, 2000.

2. Young, L.A., et al, "Design Opportunities and Challenges in the Development of Vertical Lift Planetary Aerial Vehicles," American Helicopter Society (AHS) Vertical Lift Aircraft Design Conference, San Francisco, CA, January 2000.

3. Young L.A., Aiken E.W., Gulick V.C., Mancinelli R., and Briggs G.A., Rotorcraft as Mars Scouts, 2002 IEEE Aerospace Conference, Montana, March 19-16, 2002.

4. Young, L.A., et al, "Use of Vertical Lift Planetary Aerial Vehicles for the Exploration of Mars," NASA Headquarters and Lunar and Planetary Institute Workshop on Mars Exploration Concepts, LPI Contribution \# 1062, Houston, TX, July 18-20, 2000.

5. Aiken, E.W., Ormiston, R.A., and Young, L.A., "Future Directions in Rotorcraft Technology at Ames Research Center," $56^{\text {th }}$ Annual Forum of the American Helicopter Society, International, Virginia Beach, VA, May 2-4, 2000.

6. Young, L.A., "Vertical Lift -- Not Just For Terrestrial Flight," AHS/AIAA/SAE/RaeS International Powered Lift Conference, Arlington, VA, October 30-November $1,2000$.

7. Young, L.A. and Aiken, E.W., "Vertical Lift Planetary Aerial Vehicles: Three Planetary Bodies and Four Conceptual Design Cases," $27^{\text {th }}$ European Rotorcraft Forum, Moscow, Russia, September 11-14, 2001

8. Young, L.A., et al, "Experimental Investigation and Demonstration of Rotary-Wing Technologies for Flight in the Atmosphere of Mars," $58^{\text {th }}$ Annual Forum of AHS International, Montreal, Canada, June 11-13,2002.

9. Young, L.A., et al, "Engineering Studies into Vertical Lift Planetary Aerial Vehicles," AHS International Specialist Meeting on Advanced Rotorcraft Technology and Life-Saving Activity, Utsunomiya, Japan, November 2002. 
10. Thompson, B., "Full Throttle to Mars," Rotor \& Wing, Phillips Business Information, LLC, Potomac, MD, March 2001.

11. University of Maryland Design Proposal http://www.enae.umd.edu/AGRC/Design00/MARV.ht $\underline{\mathrm{ml}}$.

12. Georgia Institute of Technology Design Proposal http://www.ae.gatech.edu/research/controls/projects/ma rs/reports/index.html

13. Datta, A., et al, "Design of the Martian Autonomous Rotary-Wing Vehicle," AHS International Specialist Meeting on Aerodynamics, Acoustics, and Test and Evaluation, San Francisco, CA, January 2002.

14. Corfeld, K., et al, "Computations on a Prototype Martian Rotorcraft," AIAA 20 $0^{\text {th }}$ Applied Aerodynamics Conference, St Louis, MO, June 24-27, 2002.

15. Pisanich, G., Ippolito, C., Plice, L, Young, L., and Lau, B., "Actions, Observations, and Decision-Making: Biologically Inspired Strategies for Autonomous Aerial Vehicles," AIAA Aerospace Sciences Conference, Reno, NV, January 2004.

16. Pisanich, G., Young, L.A., Plice, L., Ippolito, C., Lau, B., Sargent, R., and Lee, P., "Initial Efforts towards Mission-Representative Imaging Surveys from Aerial Explorers," SPIE Electronic Imaging Conference, San Jose, CA, January 2004.

17 Thakoor, S., et al, "Bioinspired Engineering of Exploration Systems for NASA and DoD," Artificial Life VIII: 8th International Conference on the Simulation and Synthesis of Living Systems, Sydney, Australia, December 9-13, 2002.

18. Plice, L., Pisanich, G., Lau, B., and Young, L.A., "Biologically Inspired 'Behavioral' Strategies for Autonomous Aerial Explorers on Mars," IEEE Aerospace Conference, Big Sky, MT, March 2003.

19. Plice, L., "Robot Economy," Robosphere 2002: Workshop on Self-Sustaining Robot Ecologies, NASA Ames Research Center, Moffett Field, CA, November 2002.

20. Pisanich, G. and Young, L.A., "An Aerobot Ecology," Robosphere 2002: Workshop on Self-Sustaining Robot Ecologies, NASA Ames Research Center, Moffett Field, CA, November 2002.

21. Ippolito, C., Plice, L., and Pisanich, G., "Holarchical Systems and Emotional Holons: Biologically-Inspired System Designs for Control of Autonomous Aerial Vehicles," $7^{\text {th }}$ World Conference on Systematics and Cybernetics, Orlando, FL, July 2003.

22. Miller, J.R., “A 3D Color Terrain Modeling System for Small Autonomous Helicopters," Doctoral Dissertation, Tech. Report CMU-RI-TR-02-07, Robotics Institute, Carnegie Mellon University, February, 2002.

23. Miller, J.R., Amidi, O., and Delouis, M., "Arctic Flight Tests of the CMU Autonomous Helicopter," $26^{\mathrm{TH}}$ Annual Symposium of the AUVSI, Baltimore, MD, 1999.

24. Miller, J.R. and Amidi, O., "3-D Site Mapping with the CMU Autonomous Helicopter," Proceedings of the $5^{\text {th }}$ International Conference on Intelligent Autonomous Systems, June 1998.
25. Sato, A., "Research and Development in Japan, Year $2000, " 57^{\text {th }}$ Annual Forum of AHS International, Washington, DC, May 9-11, 2001.

26. Onomura, Y., Suematsu, K., and Konno, F., "RPH-2A Observation System: Overview," AHS International Specialist Meeting on Advanced Rotorcraft Technology and Life-Saving Activity, Utsunomiya, Japan, November 2002.

27. Young, L.A., Aiken, E.W., Johnson, J.L., Demblewski, R., Andrews, J., and Klem, J., "New Concepts and Perspectives on Micro-Rotorcraft and Small Autonomous Rotary-Wing Vehicles," AIAA $20^{\text {th }}$ Applied Aerodynamics Conference, St Louis, MO, June 24-27, 2002.

28. Cockell, C. S., Lee, P., Osinski, G., Horneck, G., and Broady,P., "Impact-induced Microbial Endolithic Habitats," Meteoritics \& Planetary Science 37 (2002), 1287-1300.

29. Cockell, C.S. and Lee, P., "The Biology of Impact Craters - A Review," Biological Reviews, 77, pp. 279310, 2002.

30. Lee, P., Cockell, C.S., Marinova, M.M., McKay, C.P. and Rice Jr., J.W., "Snow and Ice Melt Flow Features on Devon Island, Nunavut, Arctic Canada as Possible Analogs for Recent Slope Flow Features on Mars," Lunar \& Planetary Science Conference XXXII, March 2001.

31. Osinski, G.R., Spray, J.G., and Lee, P. "Impact-induced Hydrothermal Activity Within the Haughton Impact Structure, Arctic Canada: Generation of Transient, Warm, Wet Oasis," Meteoritics \& Planetary Science 36, 731-745, 2001.

32. Osinski, G. R. and Spray, J. G., "Highly Shocked Low Density Sedimentary Rocks from the Haughton Impact Structure, Devon Island, Nunavut, Canada," Lunar \& Planetary Science Conf. XXXII, March 2001.

33. Glass, B. J. and Lee, P., "Airborne geomagnetic investigations at the Haughton impact structure, Devon Island, Nunavut, Canada," Lunar and Planetary Science XXXII, March 2001.

34. Cockell, C.S., Lee, P., Schuerger, A.C., Hidalgo, L., Jones, J.A., and Stokes, M.D., "Microbiology and Vegetation of Micro-Oases and Polar Desert, Haughton Impact Crater, Devon Island, Canada," Arctic, Antarctic, and Alpine Research 22, pp. 306-318, 2001.

35. Lee, P., "Haughton Crater and Surroundings, Devon Island, Nunavut, Arctic Canada: Significance for Astrobiology," Astrobiology Conference, NASA Ames Research Center, April 2000.

36. Lee, P., "Selective Fluvial Erosion on Mars: Glacial Selective Linear Erosion on Devon Island, Nunavut, Arctic Canada, as a Possible Analog," Lunar \& Planetary Science Conference XXXI, March 2000.

37. Osinski, G.R., Spray, J.G., Bunch, T.E., Grieve, R.A.F., Schutt, J.W., and Lee, P., "Post-Impact Hydrothermal Activity at the Haughton Impact Structure, Devon Island, Nunavut, Canada," Lunar \& Planetary Science Conference XXXI, March, 2000. 
38. Lee, P. and Rice Jr., J.W., "Small Valley Networks on Mars: The Glacial Meltwater Channel Networks of Devon Island, Nunavut Territory, Arctic Canada, as Possible Analogs," 5th Mars Conference, July 1999.

39. Lee, P., Rice Jr., J.W., Bunch, T.E., Grieve, R.A.F., McKay, C.P., Schutt, J.W., and Zent, A.P., "Possible Analogs for Small Valleys on Mars at the Haughton Impact Crater Site, Devon Island, Canadian High Arctic," Lunar \& Planetary Science Conference XXX, March 1999.

40. Lee, P., Zent, A. P., et al, “A Unique Mars Analog Site: The Haughton Impact Crater and Surroundings, Devon Island, Canadian High Arctic," Bull. Amer. Astron. Soc., 1999.

41. Zent, A.P., Bunch, T.E., Grieve, R.A.F., Lee, P., McKay, C.P., Rice Jr., J.W., and Schutt, J.W., "The Role of Brecciation in Controlling Morphology at Haughton Crater: Climatic Implications for Mars," Lunar \& Planetary Science Conference XXIX, March 98, pp. 1301-1302.

42. Whalley, M., et al, "The NASA/Army Autonomous Rotorcraft Project," 59th Annual Forum of the AHS, International, Phoenix, AZ, May 2003.

43. Hellisinki University of Technology "Rollo" BallShaped Robot Project http://www.automation.hut.fi/iecat/moving eye/home.h $\underline{\text { tml. }}$

44. Sony "Q.taro" Commercial Ball-Shaped Robot http://www.portelligent.com/tas/subscribers/archive/co mponent archive/2002 2Q/component 020410.asp

45. Chemel, B., Mutschler, E., and Schempf, H., "Cyclops: Miniature Robotic Reconnaissance System," IEEE ICRA, Detroit, MI, May 1999.

46. Hoerner, S.F., Fluid Dynamic Drag, Hoerner Fluid Dynamics, 1965.

47. Ahmad, J. and Strawn, R., "Hovering Rotor and Wake Calculations with an Overset-Grid Navier-Stokes Solver," Proceedings of the 55th Annual Forum of the American Helicopter Society, May 1999.

47. Potsdam, M. A. and Strawn, R. C., "CFD Simulations of Tiltrotor Configurations in Hover," Proceedings of the 58th Annual Forum of the American Helicopter Society, Montreal, Canada, June 11-13, 2002.

48. McMichael, J.M. and Francis, M.S., Col. USAF (Ret.), "Micro Air Vehicles - Toward a New Dimension in Flight," AUVSI Presentation, August 1997, http://www.darpa.mil/tto/mav/mav auvsi.html.

49. NASA Minority University Research and Education Program "Titan VTOL" Student Design Competition: http://www.integratedspacetechnologies.com/Titan/

\section{BIOGRAPHY}

Mr. Young has worked at NASA Ames Research Center in the area of rotorcraft research for the past twenty-two years. Mr. Young has principally focused his research on fundamental aerodynamics, advanced vehicle design, and tiltrotor technology investigations within the Aeromechanics Branch. Mr. Young is currently leading a number of advanced rotorcraft technology efforts at NASA Ames, including the study of vertical lift planetary aerial vehicles, Mars rotorcraft, and micro-rotorcraft concepts. Mr. Young is also leading the Intelligent Aerial Vehicle (IAV) effort at NASA Ames - which is sponsored by the Intelligent Systems project, an element of the NASA CICT (Computing, Information and Communications Technology) program. The IAV research focuses on the development and demonstration of bio-inspired technologies to enable/enhance autonomous aerial explorers.

\section{APPENDIX A - SRFA \& MARS ROTORCRAFT}

\section{Nomenclature}

$\begin{array}{ll}\mathrm{a} & \text { Speed of sound, } \mathrm{m} / \mathrm{sec} \\ \mathrm{A} & \text { Rotor disk area, } \mathrm{A}=\pi \mathrm{R}^{2}, \mathrm{~m}^{2} \\ \mathrm{c}_{\mathrm{do}} & \text { Rotor blade airfoil mean profile drag coefficient } \\ \mathrm{C}_{\mathrm{P}} & \text { Power coefficient, } \mathrm{C}_{\mathrm{P}}=\mathrm{P} / \rho \mathrm{AV}_{\text {Tip }}^{3} \\ \mathrm{C}_{\mathrm{T}} & \text { Thrust coefficient, } \mathrm{C}_{\mathrm{T}}=\mathrm{T} / \rho \mathrm{AV}_{\text {Tip }}^{2} \\ \mathrm{c}_{\text {Tip }} & \text { Blade tip chord length, } \mathrm{m} \\ \mathrm{k} & \text { Rotor induced power constant } \\ \mathrm{M}_{\text {Tip }} & \text { Tip Mach number, } \mathrm{M}_{\text {Tip }}=\mathrm{V}_{\mathrm{Tip}} / \mathrm{a} \\ \mathrm{N} & \text { Number of rotor blades per rotor } \\ \mathrm{P} & \text { Rotor power, watt } \\ \mathrm{R} & \text { Rotor radius, } \mathrm{m} \\ \mathrm{Re}_{\mathrm{Tip}} & \text { Tip Reynolds number } \\ \mathrm{T} & \text { Rotor thrust, } \mathrm{N} \\ \mathrm{V}_{\text {Tip }} & \text { Tip speed, } \mathrm{m} / \mathrm{sec}, \mathrm{V}_{\text {Tip }}=\Omega \mathrm{R} \\ \rho & \text { Atmospheric density } \\ \theta_{0.75} & \text { Rotor collective, blade pitch angle at } 75 \% \text { radius } \\ \Omega & \text { Rotor speed, radians/sec }\end{array}$

\section{“Vision Mission"}

This proposed mission study represents a natural transition of SRFA terrestrial investigations into Mars rotorcraft planetary science missions. The proposed Space Science Vision Mission to be studied is an augmentation of the MSL 2009 mission technology to address Mars surface exploration for any of the two study cases: 13) Search for Evidence of Past Life;14) Exploration of Hydrothermal Habitats. In both cases, advanced in situ exploration is required and this calls for 1) ability to gain access to sites and samples of interest especially in areas having steep slopes 2) ability to identify samples of special interest; 3) tools to acquire those samples, 4) high quality instrumentation to analyze samples and 5) sufficient time to take advantage of all these capabilities. 
The planned 2009 Mars Science Laboratory doubtless will be provided with a powerful suite of instruments and sample acquisition tools. It will have nuclear power ensuring long lifetime and it will have a large six-wheeled rover to provide mobility. With the planned tightening of the landing error ellipse to $\sim 10 \mathrm{~km}$ in length and the plans for a 'skycrane' soft landing, the MSL mission architecture comes close to meeting every desire for a Mars in situ mission. Nevertheless, the MSL rover will have problems in gaining access to steep slopes where much science interest lies (e.g., gullies, canyon walls, channel walls, hydrothermal vents) that is relevant to the study cases. Furthermore, because of the time required to carry out science analyses at each stopping point the MSL mission planned for 2009 is projected to have a range of mobility of only about $5 \mathrm{~km}$ even though it might be capable to travelling some hundreds of kilometers if 'turned loose' to do so.

We propose to study a mission where the mobility of the MSL is greatly enhanced by the addition of a small $(20 \mathrm{~kg})$, autonomous, rechargeable rotorcraft that is capable of creating an effective radius of operations of $\sim 10 \mathrm{~km}$, thereby opening up an area of $300 \mathrm{~km}^{2}$ to intensive exploration including high resolution spectral mapping and sample return for analysis by MSL's payload. The rotorcraft would 1) serve as a scout for the MSL, 2) would provide detailed mapping of steep slopes, and 3) would acquire samples of fines from sites inaccessible to, or distant from, MSL (Fig. 19).

The rotorcraft would land and take-off from close to the MSL and would be electrically recharged by a cable from the MSL. Mapping data would be radio-transmitted from the rotorcraft to MSL for relay to Earth. A small (Sojourner sized) service rover would be required to link the rotorcraft to the MSL for the transfer of samples and for recharging. This service rover would also be an auxiliary science platform for MSL, one that might be used to rappel down steep slopes to reach targets identified by the rotorcraft.

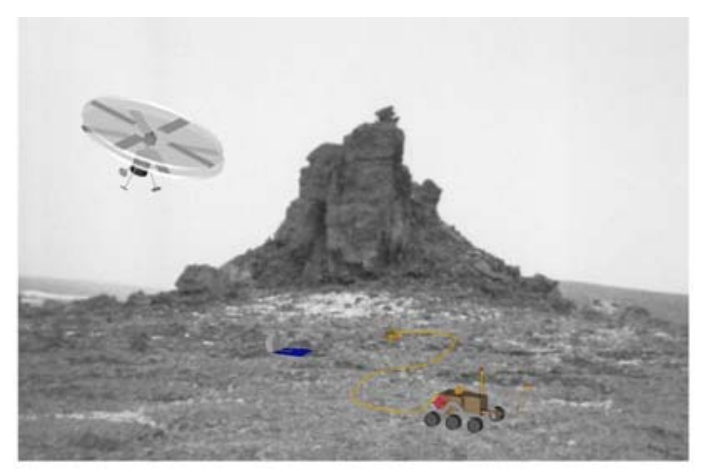

Fig. 19 - Vision Mission for the Future

\section{Ongoing Analysis}

Mars rotorcraft research continues at a modest pace at NASA Ames. Recently, the focus of the Mars rotorcraft work has been on correlation of existing experimental rotor hover data [8-9] and Navier-Stokes computational fluid dynamics (CFD) predictions [14]. Unfortunately, because of hardware apparatus problems, and operating condition limitations with the Ames environmental (vacuum) chamber, the experimental data test conditions did not exactly match the CFD conditions. The experimental data ranged from a tip mach number of 0.4 to 0.49 and a tip Reynolds number of 23,500 to 30,000 . The CFD "design target" condition was set for a tip Mach number of 0.65 and a tip Reynolds number of 50,000. It is currently impractical to repeat the CFD computations to match the test conditions for the experimental data set. An alternate, semi-empirical Reynolds number correction methodology has been employed instead.

The difference in tip Mach and Reynolds number conditions does not appear to have a significant effect on the rotor thrust versus collective trend. Note that a zero-shift pitchangle correction has been applied to the experimental data as compared to the data presented previously [8-9]. The agreement between the experimental data and the CFD predictions is quite good except for the higher thrust coefficient conditions at the lowest tip Mach and Reynolds number case, i.e. 0.4 and 23,500 respectively (Fig. 20).

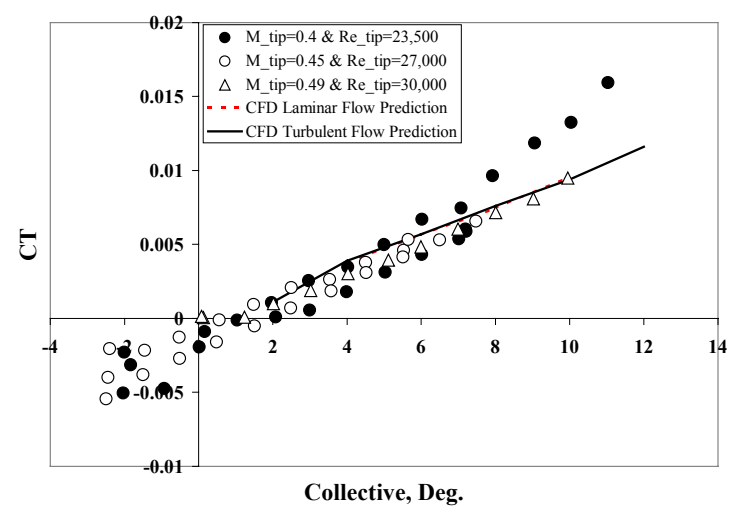

Fig. 20 - Mars Rotor Thrust Coefficient $\left(\mathrm{C}_{\mathrm{T}}\right)$ versus Collective $\left(\theta_{0.75}\right)$

The differences between experiment and prediction in terms of tip Reynolds number, however, has a profound effect on the power coefficient correlation between CFD and experimental data (Fig. 21). As an aside, it should be noted that no hub tares have been applied to the Fig. 21 experimental data. Additionally, a correction has been made to the bare shaft tares applied to the experimental data as compared to [9]. 


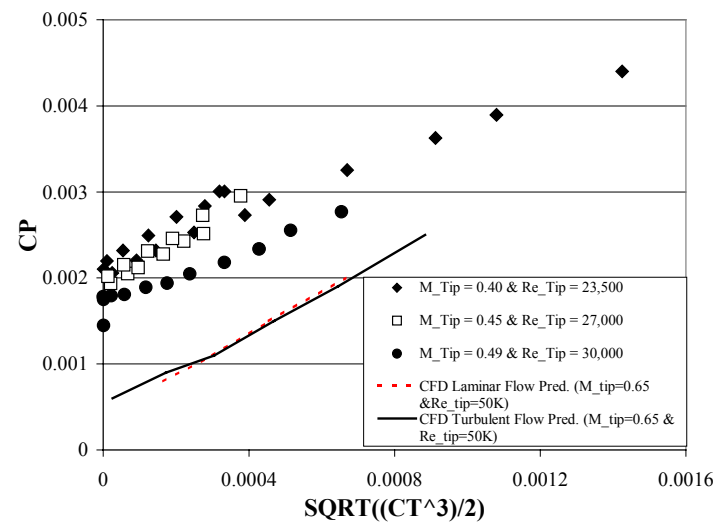

Fig.21 - $\mathrm{C}_{\mathrm{P}}$ vs $\sqrt{\mathrm{C}_{\mathrm{T}}^{3} / 2}$ (With Test/CFD Tip Mach and Reynolds Number Mismatch)

As can be seen there are considerable offsets between the CFD power predications and the experimental data. The slopes of the power versus ideal power, $\sqrt{\mathrm{C}_{\mathrm{T}}^{3} / 2}$, curves are in reasonable agreement, but the profile power (the y-axis intercept) between CFD and experiment disagree significantly. Simple linear regression of the Fig. 21 data yields the induced power contribution of the baseline Mars rotor -- in the form of the induced power constant, $\mathrm{k}$-which ranges from $\mathrm{k}=1.5$ to 2.1 . The range of numbers for $\mathrm{k}$ is quite high as compared to conventional helicopter rotors, and is likely a consequence of the large blade root cut-out of the Mars baseline rotor (resulting in a strong trailed blade root vortex) and the relatively low overall blade aspect ratio of the rotor. The design considerations for the prototype Mars baseline rotor is discussed in some detail in [8].

Fortunately, an additional set of experimental data was acquired at low collective and thrust coefficients for the Mars baseline rotor. This low thrust/collective data clearly demonstrates that profile power for low-Reynolds number rotors (including the Mars baseline rotor) is indeed profoundly influenced by the tip Reynolds number (Fig. 22). Further, using the above noted regression analysis results for the induced power constants, $\mathrm{k}$, refined estimates of the profile power as a function of Reynolds number can approximately be made. As verified by the experimental data, the Mars rotor profile power coefficient is approximately equivalent to the power coefficient measured at a collective of two deg., i.e. $\left.\mathrm{C}_{\mathrm{P}_{o}} \approx \mathrm{C}_{\mathrm{P}}\right|_{\theta_{35}=2^{\circ}}$, except at the higher Reynolds numbers tested.
Making use of the Fig. $22 \mathrm{C}_{\mathrm{P} 0}$ estimates, an empirical tip Reynolds power-law correction factor expression can be derived $\left(\mathrm{C}_{\mathrm{P} 0} \approx 7.65 \mathrm{Re}_{\mathrm{Tip}}{ }^{-0.75}\right)$ for the baseline Mars rotor. This empirical Reynolds number correction can be applied to the CFD results to determine whether or not the previously noted correlation differences do, in fact, stem from the mismatch in the specified CFD $\operatorname{Re}_{\text {Tip }}$ and the experimental test conditions.

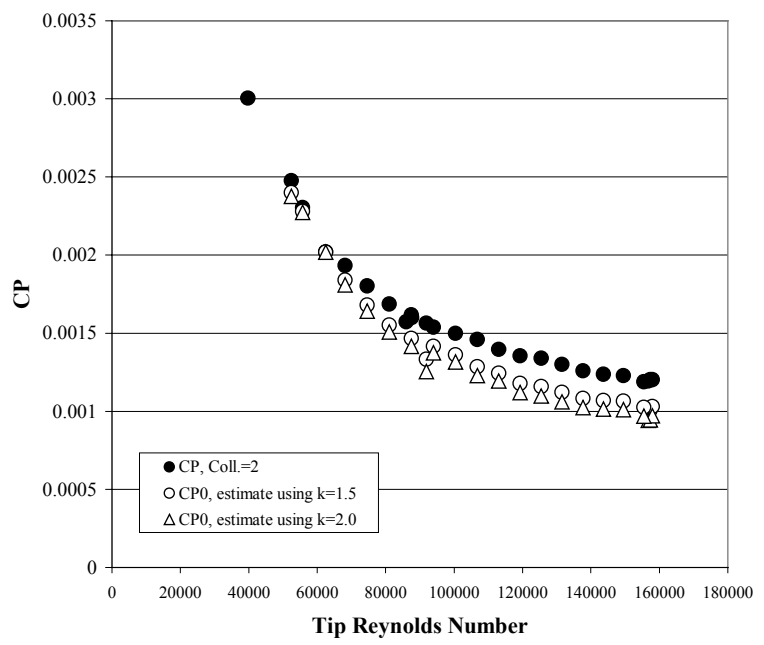

Fig. 22 - Influence of Tip Reynolds Number on Power Coefficient (low thrust/collective)

Figure 23a-c is the result of these Reynolds number corrections as applied to the CFD predictions. The power law scaling implied by the Fig. 22 data $\left(\mathrm{C}_{\mathrm{P} 0} \propto R e_{\mathrm{Tip}}^{-0.75}\right)$ is somewhat unexpected. Previous research [46] would suggest that the inboard spar (circular cylinder with flatplate inplane stiffeners) contribution to the rotor profile power would approximately scale to $\propto 1 / R e_{\text {Tір }}$ and the outer blade fairing Eppler 387 airfoil would scale $\propto 1 / \sqrt{R e_{\text {Tip }}}$ at these low-Reynolds numbers $\left(<5 \times 10^{5}\right)$. This is a subject of ongoing research. 


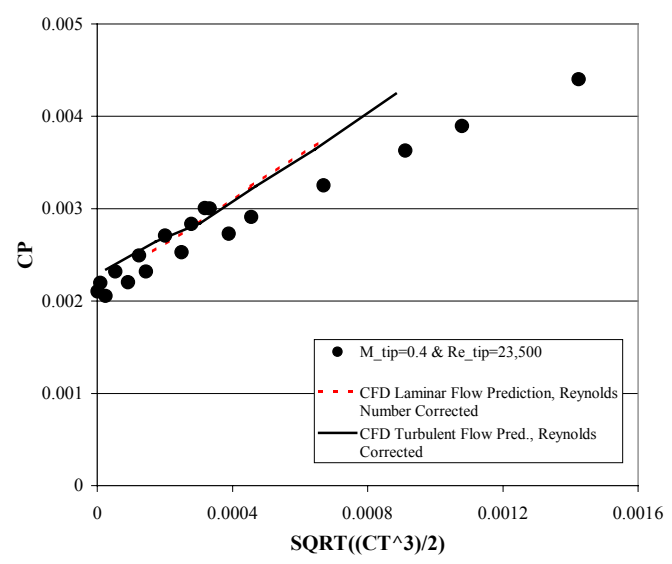

(a)

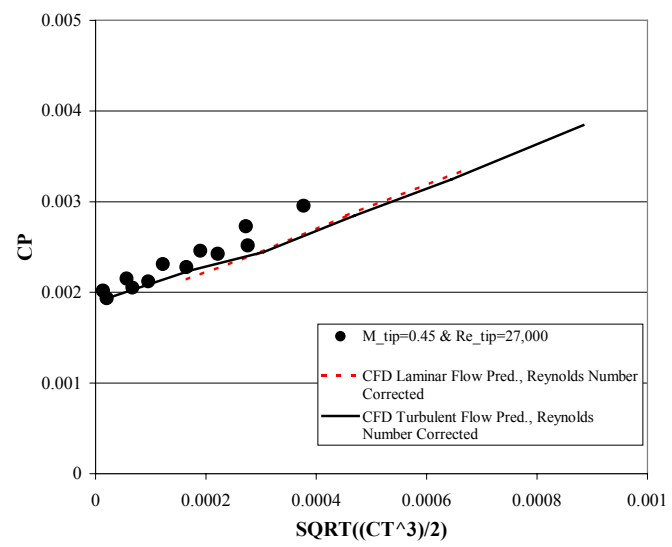

(b)

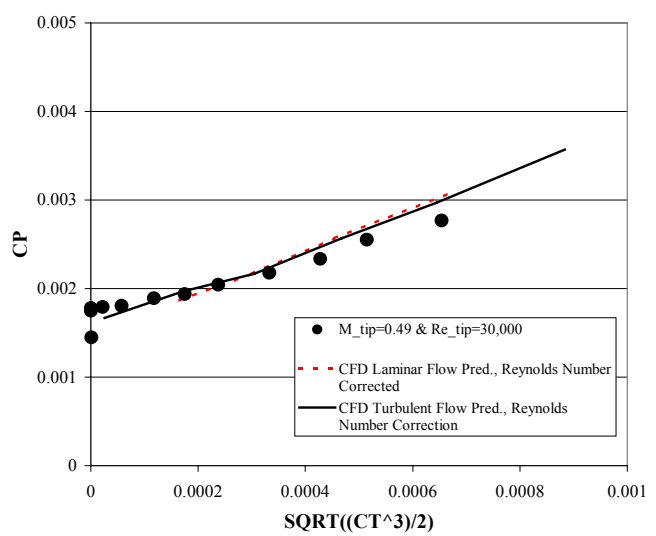

(c)

Fig. 23 - CFD Predictions: (a) Corrected to Match Data at 23,500 Tip Reynolds Number, (b) 27,000, and (c) 30,000

From the above correlation results, two conclusions can be drawn (or amplified from earlier assessments). First, the CFD predictions seem to capture the general trends of the experimental data; overall "blind-test" accuracy is comparable to similar CFD results for conventional helicopter rotors [47-48]. It is interesting to note the divergence of predicted power curve with the experimental data at $\operatorname{Re}_{T i p}=23,500$. This is to be somewhat expected as this test condition represents the greatest curve-fit extrapolation required for the profile power correction. Nonetheless, the correlation is still overall quite good. Second, the [14] CFD results - and the Fig. 23a-c trends are very encouraging as to achieving reasonable levels of profile power as tip Reynolds number is increased (to design target levels of $\sim 50,000)$. And, in fact, the [14] predictions - now validated in part by the [8-9] experimental data - lend considerable weight to engineering studies that suggest that acceptable rotor hover figures of merit can be achieved for rotors designed to operate under Mars surface atmospheric conditions.

\section{APPENDIX B - SRFA \& A STUDENT DESIGN COMPETITION}

The Army/NASA Rotorcraft Division and the NASA Ames Education Office are currently working towards sponsoring a MUREP (Minority University Research and Education Program) student design competition. The purpose of this student design competition is to perform initial conceptual design work that will ultimately lead to the development of a comprehensive "terrestrial extreme environment explorer

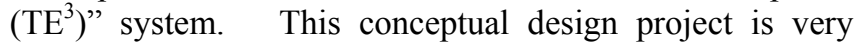
much consistent with the overarching theme of this paper -which is to place new automation/robotics tools, in particular small autonomous aerial vehicles, into the hands of field scientists. Using small cost-effective UAVs to support NASA science missions will empower researchers to achieve substantial productivity improvements. The general outline of the competition RFP and proposed rules and guidelines is noted below.

\section{Mission Assumption:}

The "terrestrial extreme environment explorer $\left(\mathrm{TE}^{3}\right)$ " system is envisioned as a small semi-automated/semiteleoperated research station that can periodically launch, recover, and service one, or more, automated aerial vehicles to conduct remote field science missions (Fig. 24). The student design teams should assume that first deployment of a $\mathrm{TE}^{3}$ system should occur by 2008 . The initial deployment should be assumed to occur at the Haughton Crater, Devon Island, Canada, Mars-analog site -- refer to http://www.marsonearth.org _ $\quad$ though subsequent deployments could be at multiple, alternate sites. The total duration of a $\mathrm{TE}^{3}$ system deployment should be assumed to be one calendar year. The objective of the $\mathrm{TE}^{3}$ system deployment is twofold: 1 . To provide field scientists robotic tools that have enhanced mobility to acquire data and to extend their effective "field season" by reducing the need for their onsite presence, or proceeding with scientific investigations in their absence; 2 . To act as a technology demonstrator as a first step to robotic colony/outpost architectures for future planetary science missions. 


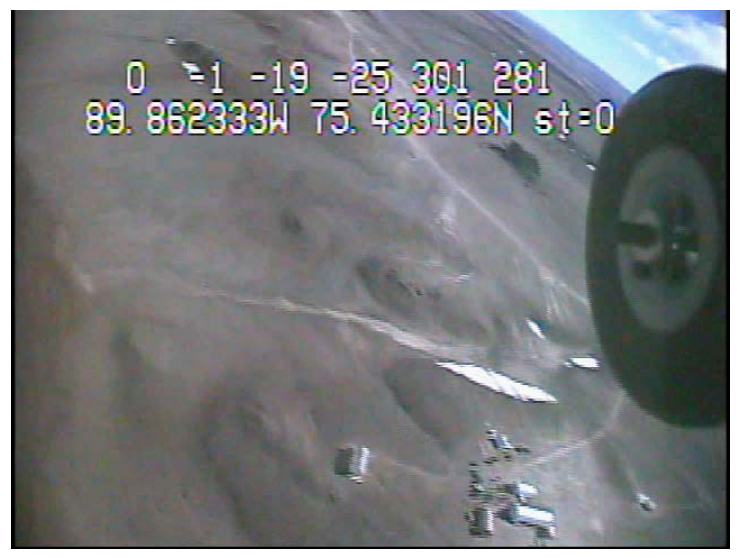

Fig. 24 - Leaving Base Camp to Explore Another Day

\section{Mission Profile \& System Requirements:}

1. The $\mathrm{TE}^{3}$ system will be comprised, as a minimum, of the following system elements: a automated hanger/station, (at least one) robotic aerial vehicle, a launch/recovery system (as needed, which could be fixed or mobile), a refueling/recharging/servicing module, a front-end data-processing unit, and a telecom system for communication with state-side "Mission Control." Optional additional elements such as teleoperated or semi-autonomous ground vehicles (rovers) might also be proposed.

2. The total $\mathrm{TE}^{3}$ system mass must be less than $1000 \mathrm{~kg}$.

3. The pre-flight gross weight of an individual aerial vehicle must be less than $100 \mathrm{~kg}$. Conceptual design trade studies by the student teams will examine/identify the appropriate aerial vehicle weights for specified $\mathrm{TE}^{3}$ mission.

4. The total cost of $\mathrm{TE}^{3}$ system should be less than $\$ 500 \mathrm{~K}$, excluding nonrecurring-engineering costs. Both the fabrication/development costs and the engineering costs should, though, be estimated in the student team proposals.

5. The electrical power for the hanger/station will be derived from a combination of wind turbine and solar power.

6. The aerial vehicle(s) should be capable of being launched and recovered in wind speeds up to $13 \mathrm{~m} / \mathrm{sec}$ (25 knots).

7. The aerial vehicles should be able to have a minimum of half-hour endurance, and have a minimum radius of operation of $10 \mathrm{~km}$.
8. The aerial vehicles can be fueled either by automotive gasoline or electric propulsion. The $\mathrm{TE}^{3}$ system design must discuss the semi-automated approach to refueling/recharging.

9. The aerial vehicles must be capable of self-starting.

10. The aerial vehicle(s) can be assumed to operate autonomously with GPS waypoint navigation. The aerial vehicles can operate out of line of sight communication, and telemetry and data are stored onboard the vehicle, for future downlink/transfer at the hanger/station.

11. The following is the nominal level of sorties to be carried out by the aerial vehicles: 1 . During month of July one flight every two days; 2. During May, June, August, and September one flight per week; 3. Rest of the year, one flight per month.

12. During "winter" months, when there is little or no daylight, aerial vehicles must carry non-visible wavelength (or non-optic) sensors as a part of their science payload.

13. Ten percent of the aerial vehicle gross weight should be assumed to account for aerial vehicle payload. The student teams will be required to define the science sensors (both ground and air assets) for the $\mathrm{TE}^{3}$ system.

\section{Constraints \& Assumptions:}

1. All $\mathrm{TE}^{3}$ system equipment should be transportable in one Twin Otter aircraft to the analog site. Individual pieces of equipment should be no more than $200 \mathrm{~kg}$ and contained in a crate no larger than 1 meter by 2 meter by 2.5 meter.

2. The $\mathrm{TE}^{3}$ system should require no more than two weeks assembly and onsite checkout by a team of four technical staff.

3. The siting of the $\mathrm{TE}^{3}$ system can be assumed optimally selected by the technical staff team to allow for safe launch and recovery of the aerial vehicle (i.e. for example it being sited near a dry lakebed for landing).

4. The following weather conditions should be assumed: TBD. Maximizing flight opportunities during severe weather will be an important design consideration to the $\mathrm{TE}^{3}$ system. Dealing with heavy snow blankets during aerial vehicle launch and recovery (and access into and out of the hanger/station) will be an important consideration in the $\mathrm{TE}^{3}$ system design.

5. Expendable aerial vehicles are not prohibited by the rules of this competition, if shown to be cost-effective and otherwise desirable. 